\title{
SISTEMAS SINÓTICOS ASSOCIADOS ÀS PRECIPITAÇÕES INTENSAS NO ESTADO DE ALAGOAS
}

\author{
BRUCE FRANCISCO PONTES DA SILVA ${ }^{1}$, NATALIA FEDOROVA ${ }^{2}$, VLADIMIR LEVIT ${ }^{2}$, ANATOLY \\ PERESETSKY ${ }^{3}$ E BRUNO MIRANDA DE BRITO ${ }^{4}$
}
${ }^{1}$ Universidade de São Paulo, Instituto de Astronomia, Geofísica e Ciências Atmosféricas, Departamento de Ciências Atmosféricas (USP/IAG/DCA), São Paulo, SP, Brasil
${ }^{2}$ Universidade Federal de Alagoas, Instituto de Ciências Atmosféricas (UFAL/ICA), Maceió, AL, Brasil
${ }^{3}$ New Economic School, Moscow, Rússia
${ }^{4}$ Instituto nacional de Pesquisas Espaciais, Centro de Previsão de Tempo e Estudos Climáticos (INPE/
CPTEC), São José dos Campos, SP, Brasil

brucepontes@model.iag.usp.br, nataliabras@gmail.com, vlevit@dimin.net, apereset@nes.ru, bruno. miranda@cptec.inpe.br

Recebido Junho 2009 - Aceito Dezembro 2010

\begin{abstract}
RESUMO
Neste trabalho analisou-se a estrutura dos sistemas meteorológicos associados às precipitações intensas em Alagoas entre 2003 e 2006. Foi feita a análise das imagens de satélite no canal infravermelho, de produtos de reanálise do National Centers for Environmental Prediction (NCEP) e dados de precipitação de dezessete postos pluviométricos, espalhados em diferentes regiões do Estado. $\mathrm{O}$ objetivo desse estudo foi analisar as causas da formação das precipitações intensas e determinar os sistemas meteorológicos associados. Os casos de precipitação intensa foram registrados no Outono/ Inverno. Além disso, metade dos eventos ocorridos entre a primavera e o verão aconteceu em janeiro. As Perturbações Ondulatórias nos Ventos Alísios, a Corrente de Jato do Nordeste Brasileiro e as extremidades das frentes frias foram os sistemas que estiveram mais relacionados às precipitações intensas. Complexos Convectivos de Mesoescala provocaram boa parte dos temporais no oeste do Estado, o que não foi verificado no leste. Exemplificando o método de análise utilizado, um caso foi discutido.

Palavras-chaves: Sistemas Sinóticos, Precipitações Intensas, Alagoas.
\end{abstract}

\section{ABSTRACT: SYNOPTIC SYSTEMS ASSOCIATED TO HEAVY PRECIPITATION IN THE} STATE OF ALAGOAS

Structures of meteorological systems, associated with heavy precipitation in the Alagoas State, for the 2003-2006 period were studied. Infrared satellite images, reanalysis data products of the National Centers for Environmental Prediction (NCEP) and data from seventeen Alagoas pluviometric stations were used. The goal of this study is the analysis of the heavy precipitation causes and determination of the associated weather systems. Heavy precipitations were usually registered during autumn/ winter seasons. Also, half of all spring/summer heavy precipitations events occurred in January. Wave Disturbances in the Trade Winds, Brazilian Northeast Jet Streams and Cold Front Extremities were associated with heavy precipitations. Almost all heavy precipitations events were connected with Mesoscale Convective Complexes in the west region of the State and usually did not occur in the east region. To exemplify the used analysis method a case study is discussed.

Keywords: Synoptic Systems, Heavy Precipitation, Alagoas. 


\section{INTRODUÇÃO}

Alagoas tem como base econômica a agricultura e pecuária, a Indústria e o Turismo. Boa parte destes é intensamente afetada pelas condições de tempo e clima, dependendo delas para a tomada de decisões. Assim, o estudo da frequência e da intensidade das precipitações é de elevada importância, em especial o estudo das precipitações intensas, pois tanto no meio urbano, como nas áreas rurais, acarretam transtornos. Estes transtornos são responsáveis por destruições de bens materiais e de perdas humanas (Marques, 2008), principalmente em função de inundações e deslizamentos de terra. Uma maneira prática de se amenizar o efeito desse problema é ter ciência dos sistemas produtores de precipitações intensas e, a partir daí, desenvolver métodos que possam prognosticar a formação dos processos que darão origem àqueles sistemas. O que não é tarefa fácil, pois a região nordeste do Brasil, que inclui Alagoas, situa-se numa área em que os processos tropicais interagem com os processos das latitudes médias, dificultando a identificação dos sistemas, os quais combinados poderão gerar precipitações intensas, definidas na seção 2.2 .

Os mecanismos de formação e desenvolvimento dos sistemas meteorológicos que afetam o Estado ainda não foram plenamente estabelecidos, o que significa que uma previsão de tempo, com alto grau de acerto, dificilmente poderá ser feita. Especialmente tratando-se da previsão de precipitações intensas, onde um estudo recente (Santos, 2008) revelou que, no ano de 2007, as previsões de tempo para Maceió publicadas nos jornais Folha de São Paulo (previsão elaborada pelo CPTEC) e Gazeta de Alagoas (fonte de previsão não citada na época das publicações ${ }^{1}$ ), obtiveram resultados pouco satisfatórios. Em todos os dias com registro de chuvas significativas, os jornais não publicaram uma previsão adequada para o tempo observado. Também é digno de nota que outros fenômenos, tais como trovoadas, nevoeiros e ventos fortes não foram previstos nenhuma vez. O jornal Gazeta de Alagoas destacou "nebulosidade variável sem chuva" nos dias em que se observaram chuvas irrisórias ou sua ausência na capital alagoana em $25 \%$ das previsões publicadas, utilizando "nebulosidade variável com chuva isolada" nos dias com registro de precipitações moderadas ${ }^{2}$ ( $74 \%$ de suas publicações). A Folha de São Paulo publicou "nebulosidade variável sem chuva" em $20 \%$ das previsões e "nebulosidade variável com chuva isolada" em outras $76 \%$, resultado que se aproxima ao obtido na análise de previsões publicadas pela Gazeta de Alagoas.

\footnotetext{
${ }^{1}$ Santos (2008) informou em seu trabalho que a Gazeta de Alagoas não apresentava a fonte de sua previsão de tempo nos jornais em 2007. Atualmente, a mesma é parceira da Climatempo.

${ }^{2}$ A classificação feita pelo autor considera uma precipitação como fraca se em 24 o acumulado for de até $1,96 \mathrm{~mm}$, moderada se tal valor estiver entre 1,97 e $23,5 \mathrm{~mm}$ e forte se o mesmo for maior ou igual a $23,6 \mathrm{~mm}$.
}

Cavalcanti et al. (2008) observaram que os dados do modelo ETA mostraram-se mais confiáveis do que os dados de reanálise do NCEP, para o estudo termodinâmico da atmosfera no estado de Alagoas, apesar dos resultados pouco satisfatórios. O modelo ETA de resolução espacial de $15 \times 15 \mathrm{~km}$ usado no estudo, previu 7 dias de precipitação intensa no período abrangido (2003 a 2006), sendo que em 3 a previsão foi correta. No entanto, foram registrados, via dados convencionais de postos pluviométricos, 27 dias com registro de precipitações intensas.

Em suas pesquisas, Alves et al. (2001) concluíram que os sistemas meteorológicos que afetam o tempo no leste do NEB precisam ser estudados mais detalhadamente. Entre esses sistemas, os Complexos Convectivos de Mesoescala (CCM) e Vórtices Ciclônicos de Altos Níveis (VCAN) foram destacados em seus estudos (Alves et al., 2001; 2006). Um trabalho anterior aos citados, sobre a possível ligação entre o fenômeno El Niño-Oscilação Sul (ENOS) e o clima no setor leste nordestino foi realizado, sendo uma rica fonte de informação, uma vez que poucos estudos sobre o assunto foram elaborados (Alves et al., 1997). Molion e Bernardo (2002) discorreram sobre os sistemas relacionados às precipitações no NEB, incluindo o leste da região.

Além dos trabalhos mencionados, outros estudos revelaram que realmente são necessários métodos eficientes na elaboração de previsões de tempo e clima, não só para Alagoas como para todo o leste do nordeste brasileiro. Tais métodos só podem ser desenvolvidos a partir do conhecimento pleno dos mecanismos envolvidos na formação dos fenômenos adversos. Nesse intuito, foi criado o projeto internacional "Desenvolvimento de métodos para previsão em curto prazo dos fenômenos meteorológicos adversos que afetam a economia do estado de Alagoas", um convênio entre Brasil e Rússia, que vem avaliar a previsão de precipitações em Alagoas através de métodos variados, tais como: métodos estatísticos, econométricos, termodinâmicos e sinóticos, a partir de modelos de alta resolução, visando melhores resultados. Como parte integrante desse projeto, o presente estudo apresenta a análise sinótica dos sistemas meteorológicos que atuaram no período examinado.

\section{MATERIAIS E MÉTODOS}

\subsection{Dados para a Análise Sinótica}

Três bancos de dados, compreendendo os anos de 2003 a 2006, foram providenciados para que a análise sinótica pudesse ser realizada satisfatoriamente. O período de análise escolhido foi o mesmo para todas as partes do estudo e tipos de dados, mencionados na introdução. Este período foi restrito em função 
do período de funcionamento do modelo ETA de alta resolução. Tais bancos de dados estão devidamente enumerados:

i. Imagens compostas dos satélites GOES e METEOSAT no canal infravermelho para todo o período de análise, obtidas no site do Centro de Previsão de Tempo e Estudos Climáticos do Instituto Nacional de Pesquisas Espaciais (CPTEC/INPE): http://www.cptec.inpe.br e imagens no mesmo canal do Satélite GOES-12, disponibilizadas pelo Space Science and Engineering Center Images and Data (SSEC) da Universidade de WisconsinMadison: http://dcdbs.ssec.wisc.edu/inventory/.

ii. Produtos de reanálise do modelo numérico do National Centers for Environmental Prediction (NCEP) ligado à National Oceanic and Atmospheric Administration (NOAA), logrados através da página da internet do Climate Research Data and Resources (CDC): http://www.cdc.noaa.gov (Kalnay et al., 1996).

iii. Dados meteorológicos convencionais fornecidos pelo Departamento de Controle do Espaço Aéreo (DECEA), pela Diretoria de Meteorologia da Secretaria de Estado do Meio Ambiente e dos Recursos Hídricos de Alagoas (DMETSEMARH/AL) e através do Programa de Monitoramento Climático em Tempo Real da Região Nordeste (PROCLIMA): http://www.cptec.inpe.br/proclima/.

Os dados de satélites, em diferentes horários (todos aqueles disponíveis nos sites na época da compilação dos bancos de dados), serviram para identificar os sistemas sinóticos no caso de precipitações intensas em Alagoas, assim como para estudar o seu deslocamento e evolução.

Para os dados de reanálise do NCEP, foram utilizados os campos de análise das linhas de corrente e magnitude do vento nos níveis de 1000, 850, 700, 500, 300 e 200 hPa na área correspondente às coordenadas de $20^{\circ} \mathrm{N}$ a $60^{\circ} \mathrm{S}$ de latitude e $20^{\circ} \mathrm{W}$ e $85^{\circ} \mathrm{W}$ de longitude (Leste do Pacífico, América do Sul e Oceano Atlântico Sul) nos horários de 00, 06, 12 e 18UTC. Para a devida visualização dos dados citados, foi utilizado o software Grid Analysis and Display System (GrADS).

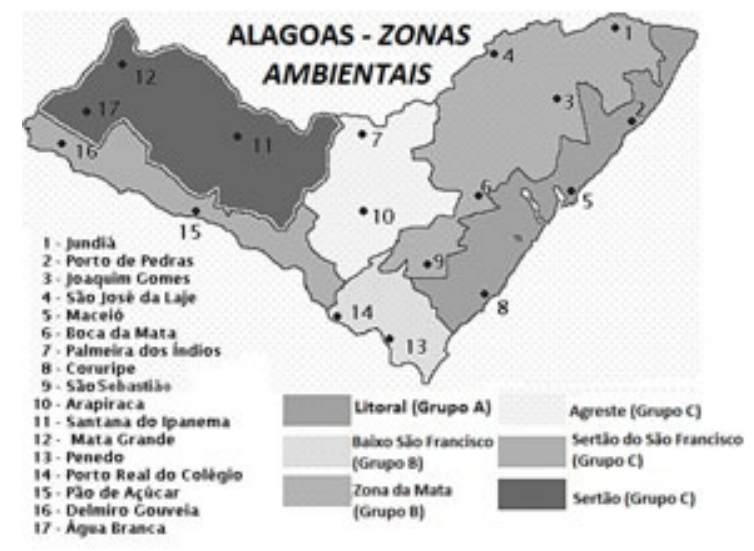

Os dados meteorológicos convencionais contribuíram para a avaliação da intensidade das precipitações e sua consequente escolha para o estudo dos casos com precipitações intensas. Segundo o Manual de Observações Meteorológicas do INMET, chuvas com intensidades $\geq 60 \mathrm{~mm} / \mathrm{h}$, entre 5 e $60 \mathrm{~mm} / \mathrm{h}$ e de 1 a $5 \mathrm{~mm} / \mathrm{h}$ são consideradas como fortes, moderadas e fracas, respectivamente (INMET, 1999). Não há uma classificação oficial em termos diários ( $\mathrm{mm} /$ dia).

Fazendo-se uso de tais dados e dos devidos métodos sinóticos, foram determinados os sistemas e processos físicos que podem resultar na ocorrência de precipitações intensas no estado de Alagoas.

\section{2 Área de Abrangência do Estudo e Identificação das Precipitações Intensas}

Foram selecionados dezessete postos pluviométricos (Figura 1, esquerda) localizados em diferentes zonas ambientais do Estado de Alagoas para o estudo das precipitações intensas.

O Manual de Observações Meteorológicas do INMET (INMET, 1999) não especifica quando se deve classificar uma precipitação como intensa ou não em termos diários, isto é, o acúmulo de água precipitada num período de 24 horas e, tampouco existem padrões para sua determinação nesse caso. Portanto, a qualificação do grau de intensidade de uma precipitação dependerá das mais variadas características do local onde ela ocorrerá: tipo e condições de relevo e vegetação, caráter do sistema de drenagem, entre outras.

A utilização dos métodos tradicionais na escolha dos limites para classificar uma precipitação como sendo intensa não foi possível devido às razões descritas a seguir. As distribuições de precipitações mostram grandes desvios relativos às distribuições gaussianas (normais), conforme salienta o INMET na seção Clima de seu site (http://www.inmet.gov.br/html/clima/ clima.html - Acesso em: 2008), ao explanar sobre as anomalias

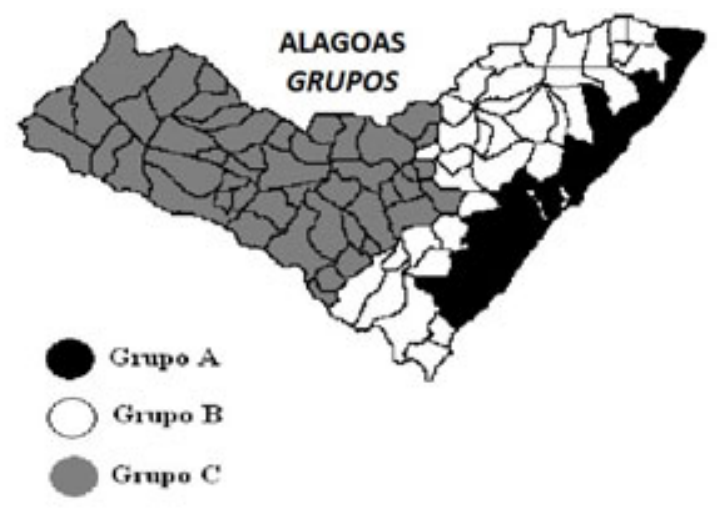

Figura 1 - Mapa das regiões ambientais alagoanas e localização dos postos pluviométricos utilizados (esquerda) e grupos estudados (direita). Fonte: adaptado de SEMARH/AL (2008). 
de precipitação. O instituto salienta que todos os totais diários de precipitação, vários mensais e alguns anuais, têm distribuições que notoriamente não são normais. Além disso, aqueles totais diários, alguns mensais e uns poucos anuais contêm valores de não ocorrência (zero). Esta última característica distingue as distribuições de freqüências da precipitação de vários outros parâmetros meteorológicos. Isso mostra que o uso tradicional da média aritmética e do desvio padrão é inadequado para a análise das diferenças verificadas entre os dados observados e a climatologia (médias históricas), podendo conduzir a interpretações equivocadas. Dessa feita, o INMET decidiu adotar dois métodos alternativos para caracterizar os desvios de precipitação: o método dos $\mathrm{DECIS}^{3}$ e o $\mathrm{SPI}^{4}$ (Standardized Precipitation Index - Índice de Precipitação Padronizado), métodos que também não seriam de muita ajuda no presente estudo, isso porque tais índices não se aplicam na análise diária de precipitações, mas sim de valores cumulativos, o que não condiria com a realidade abordada aqui, ou seja, valores diários de precipitação.

Logo, através da análise dos arquivos especializados de dados de precipitação e de satélites, assim como dos produtos do modelo do NCEP, foi adotada a seguinte metodologia: a) serão consideradas intensas aquelas precipitações em que o total diário de chuva se igualar ou exceder os $100 \mathrm{~mm}$ no Litoral (GRUPO A); b) $60 \mathrm{~mm}$ na Zona da Mata e Baixo São Francisco (GRUPO B); c) no caso do Agreste, Sertão e Sertão do São Francisco (GRUPO C), somente quando o valor de chuva diário for igual ou superior a $40 \mathrm{~mm}$ as precipitações serão apontadas como intensas. A área abrangida por cada grupo está exposta no lado direito da Figura 1.

A escolha dos valores superiores a $100 \mathrm{~mm}$ diários no GRUPO A baseou-se na orientação do Manual de Observações Meteorológicas do INMET, que considera como dia em que ocorreu chuva todos os dias em que o acumulado de precipitação em $24 \mathrm{~h}$ foi igual ou superior a $0,1 \mathrm{~mm}$. Este valor corresponde a $1 / 3$ da normal climatológica de precipitação para esse grupo no mês mais chuvoso, sendo considerado crítico pelo INMET, uma vez que pode causar transtornos na região. O mês mais chuvoso entre 1974 e 2004 no GRUPO A foi Junho, com $300 \mathrm{~mm}$. Em razão disso, nos demais grupos foi utilizada a mesma relação, ou seja, 1/3 do valor da normal climatológica de precipitação para o mês mais chuvoso. De acordo com a Diretoria de Meteorologia da SEMARH/AL, o mês mais chuvoso no GRUPO B entre 1974 e 2004 foi Julho,

\footnotetext{
${ }^{3}$ É um índice muito utilizado como indicador de secas e oferece uma medida estatística exata do padrão da precipitação mensal, requerendo apenas uma série longa de registros climáticos de precipitação pluviométrica (pelo menos 30 anos de dados)

${ }^{4} \mathrm{O}$ SPI corresponde ao número de desvios padrão de que a precipitação cumulativa observada se afasta da média climatológica, para uma variável aleatória com distribuição normal.
}

com valor médio de $190 \mathrm{~mm}$ acumulados de precipitação. No GRUPO C, o mês mais chuvoso naquele mesmo período foi Junho, com valor médio de $110 \mathrm{~mm}$.

A utilização desses valores também foi função do fato de que, nos anos pesquisados, observou-se apenas um caso com registrado de totais diários de precipitação iguais ou superiores a $100 \mathrm{~mm}$ no GRUPO B, e nenhum caso nos postos pluviométricos que representam o GRUPO C.

\subsection{Sistemas Sinóticos causadores de tempo em Alagoas}

Diversos Sistemas Sinóticos provocam, direta ou indiretamente, precipitações em Alagoas. Dentre eles, podem-se citar os Sistemas Frontais (SF) ou suas extremidades, que são caracterizados por uma região de limite entre duas massas de ar que possuem características diferentes, como temperatura, umidade e instabilidade (Kousky, 1979; Souza e Costa, 1994; Gemiacki, 2005; Cruz, 2008). A Zona de Convergência Intertropical (ZCIT) é um cinturão composto por aglomerados de nuvens convectivas, oriundas da confluência entre os ventos alísios de nordeste e sudeste na região equatorial. Em alguns casos, a ZCIT consegue influenciar o tempo em Alagoas, muitas vezes indiretamente, isto é, via "pulsos" de nebulosidade que se desprendem de sua área de maior atuação e se dirigem para sul, atingindo o Estado (Hubert et al., 1969, Uvo e Nobre., 1989; Ferreira, 1996; Xavier et al., 2000; Coelho-Zanotti et al., 2004).

Também devem ser mencionados os Vórtices Ciclônicos de Altos Níveis (VCAN), circulação ciclônica situada nos altos níveis da troposfera (Gan e Kousky, 1986; Kousky e Gan, 1981; Rao e Bonatti, 1987; Mishra et al., 2007). Além dos VCANs, podem ser observados Vórtices Ciclônicos de Médios Níveis (VCMN) no NEB, circulação ciclônica dos ventos observada somente em médios níveis da atmosfera (Fedorova et al., 2006) AAlta ou Anticiclone Subtropical do Atlântico Sul (ASAS) tem um papel importante no regime de chuvas no leste do NEB, pois é observado que no período chuvoso dessa região, sua circulação advecta umidade do oceano em direção ao continente sul-americano, ajudando no processo de convergência do fluxo de umidade na costa nordestina, o que reforça a instabilidade na região (Bastos e Ferreira, 2000).

Outro sistema importante são as Ondas ou Distúrbios Ondulatórios de Leste (OL), perturbações associadas a cavados (prolongamentos de uma área de baixa pressão na atmosfera), mais bem configurados em médios níveis da troposfera $(700$, $500 \mathrm{hPa}$ ), e à temperatura elevada na superfície do mar, onde sua nebulosidade é caracterizada por nuvens convectivas que se deslocam de leste para oeste nos oceanos, atingindo áreas continentais da costa leste do NEB (Espinoza, 1996; VarejãoSilva, 2005; Coutinho e Fritsch, 2007). 
Sistemas meteorológicos de escala menor que a dos anteriormente citados (Sistemas de Mesoescala) ainda devem ser mencionados como, por exemplo, os Complexos Convectivos de Mesoescala (CCM), que são aglomerados de nuvens de forte desenvolvimento vertical, produtoras de precipitações intensas (Maddox, 1980, 1983; Velasco e Fritsch, 1987; Silva Dias 1987; Reeder e Smith, 1998; Alves et al., 2001). Fedorova et al. (2004) estudaram um caso de CCM que atingiu o leste de Alagoas, provocando precipitações intensas em Maceió, capital do Estado. Num estudo mais recente, foram analisados os fatores que deram origem a um intenso CCM sobre o oeste desse Estado, resultando em precipitações consideráveis, fortes descargas elétricas e até queda de granizo (Pontes et al., 2008a e 2008b).

De grande importância no regime de chuvas em Alagoas são as Perturbações Ondulatórias no Campo dos Ventos Alísios (POAs, Molion e Bernardo, 2002). Esses distúrbios são formados pela convergência dos ventos que acompanham os Sistemas Frontais com os ventos alísios. Dão origem à grande nebulosidade ao se aproximarem de áreas costeiras, devido à convergência do fluxo de umidade e contraste de temperatura entre oceano e continente. Também sistemas mais localizados, como as brisas de terra e mar e a convecção local, não podem ser descartados como mecanismos contribuidores nos totais pluviométricos observados no Estado.

Uma corrente de ventos fortes, em níveis superiores, atuante no NEB, chamada de Corrente de Jato do Nordeste Brasileiro (CJNEB) foi investigada por Gomes (2003). Esse autor observou uma atuação maior da CJNEB no inverno austral, assim como ocorre no caso da Corrente de Jato Subtropical da América do Sul (Pezzi et al., 1996). Em muitos casos, esses sistemas são vistos através de imagens de satélite, apresentando nebulosidade predominantemente cirriforme (Valovcin, 1968; Doswell e Schaefer, 1976; Rao et. al., 1990). Posteriormente, ao estudar a influência da CJNEB, particularmente em Alagoas, Campos e Fedorova (2006) encontraram 73 dias de ocorrência do fenômeno no ano de 2004, onde os valores da velocidade máxima do vento no seu eixo chegaram a $60 \mathrm{~m} / \mathrm{s}$. Também observou-se a ligação da CJNEB com VCANs, VCMNs e correntes de Jato de Baixos Níveis (CJBN), sendo que alguns sistemas sofreram mudança na sua estrutura em razão das circulações transversais da CJNEB. Quanto aos fenômenos adversos gerados pela CJNEB em Alagoas, Campos e Fedorova (2006) destacou a formação de névoa úmida e seca, chuva leve intermitente, nevoeiro e pancadas de chuva. As distribuições espaciais típicas da CJNEB observadas foram: de norte para o sul, nordeste para sudoeste, sudeste para nordeste, noroeste para sudeste e zonal.

\subsection{Procedimento para a Análise dos Dias com Precipitações Intensas e Identificação dos Sistemas Sinóticos Associados}

Com o auxílio das imagens compostas pelos satélites GOES e METEOSAT e GOES-12, foi possível identificar os Sistemas Sinóticos e de Mesoescala que atuaram em Alagoas e regiões circunvizinhas, assim como acompanhar sua evolução. As imagens selecionadas foram aquelas nas quais os seus horários correspondentes proporcionaram a melhor visualização, e identificação possível, de cada sistema atmosférico atuante nos dias onde houve registro de precipitações intensas.

A observação do campo de linhas de corrente e magnitude do vento seguiu o padrão adotado para a escolha das imagens de satélite, ou seja, elegeram-se apenas os campos relativos aos horários que confirmassem a existência dos sistemas previamente vistos através das imagens de satélite. Os horários das imagens de satélite e de linhas de corrente e magnitude do vento analisados nem sempre coincidem. Portanto, se fez uso dos campos de reanálise do NCEP contendo os horários mais próximos das imagens de satélite. A diferença máxima entre os horários foi de 15 minutos.

Os mapas expositores de Linhas de Corrente foram confeccionados levando-se em conta cada nível troposférico: baixos, médios e altos níveis. Em baixos níveis foram construídos os mapas correspondentes os níveis de 1000 e 850 $\mathrm{hPa}$. Em médios níveis foram utilizados os níveis isobáricos de 700 e $500 \mathrm{hPa}$. E nos níveis mais altos, foram construídos os campos de Linhas de Corrente para 300 e $200 \mathrm{hPa}$. Para uma visualização panorâmica da circulação dos ventos, igualmente se construiu mapas de linhas de corrente no plano vertical, abrangendo os níveis previamente citados.

A construção desses mapas, em cada nível, facilitou a identificação dos Sistemas Sinóticos e de Mesoescala associados aos casos de precipitação em Alagoas, já que através da circulação exposta neles, pôde-se notar a atuação de cavados (cristas), ciclones (anticiclones) e a confluência (difluência) dos ventos em cada nível. Em muitos casos, o que inclui alguns eventos de precipitação intensa, notou-se que este último tipo de circulação foi crucial em seu desenvolvimento.

Também foram confeccionadas as seções verticais dos movimentos do ar para os postos pluviométricos mais afetados pelos eventos extremos, especialmente nos casos mais complexos, visto que os movimentos ascendentes ou descendentes têm um papel de extrema importância na manutenção de certos sistemas meteorológicos. Para essa classe de casos, igualmente foram construídos perfis verticais simulados para os postos pluviométricos mais afetados pelas precipitações intensas. O cálculo dos índices de instabilidade (K, LI e TT) e da energia potencial disponível para convecção (CAPE) complementou a análise sinótica. Esses campos tornaram-se indispensáveis ao analisar os casos em que dois ou mais sistemas foram identificados como sendo responsáveis pela formação das precipitações. 


\section{RESULTADOS E DISCUSSÃO}

\subsection{Frequência das Precipitações e Sistemas Meteorológicos Associados}

A Tabela 1 mostra a média aritmética do número de dias onde se registrou precipitação, a partir de 0,1 mm (INMET, 1999), para os dezessete postos pluviométricos estudados, assim como a sua média anual e por período para cada posto.

Os anos de 2003 e 2004 foram, respectivamente, aqueles nos quais se registrou uma maior quantidade no número de dias com precipitação (210 e 209, respectivamente) em Alagoas, sendo que 2006 foi o ano que totalizou a menor quantidade de dias com precipitação (186). Todavia, a variação anual é pequena. Em média, ocorreram 201 dias de chuva em Alagoas, como um todo, nos anos usados como base. $\mathrm{O}$ ano de 2004 foi aquele que contabilizou um maior total no que se diz respeito ao número de dias com registro de precipitação, com 210 dias, conforme a metodologia utilizada.

O número de dias com precipitação foi maior nos meses de outono/inverno do que nos de primavera/verão, o que condiz com o período chuvoso do Estado (abril a julho). Contudo, a média do número de dias com precipitação variou conforme a zona ambiental estudada. A título de exemplo, nos postos pluviométricos localizados no Sertão e Sertão do São Francisco, a média do número de dias com precipitação foi $31 \%$ menor que a média dos postos situados nas demais zonas ambientais do Estado.

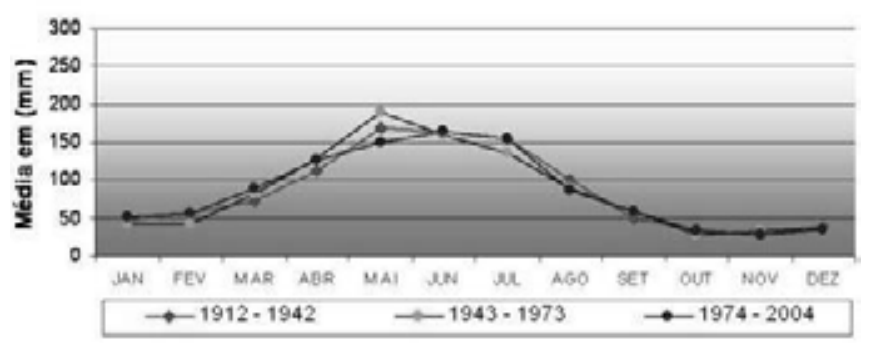

Figura 2 - Normais climatológicas de precipitação em Alagoas em três períodos distintos.

FONTE: SEMARH/AL.

A média de dias com registro de chuva em Alagoas oscilou proporcionalmente à passagem dos meses, isto é, cresceu aos poucos no primeiro semestre e, a partir daí, decresceu velozmente até o final do semestre seguinte, fazendo uma distinção razoável entre o período chuvoso e o seco. As estações de transição, isto é, outono e primavera, se encaixaram quase que perfeitamente como sendo o marco do início e fim, respectivamente, do período chuvoso em Alagoas, como pode ser visto claramente através da curva da Figura 2. O resultado da média de dias com precipitação obtida para os anos de 2003 e 2006 concorda, em parte, com os resultados obtidos em estudos prévios sobre a distribuição das chuvas no Estado, os quais mencionaram o período entre o Outono e Inverno como sendo aquele mais chuvoso no Estado e no leste do NEB como um todo (Santos et al., 2002; Gois et al., 2005).

Tabela 1 - Média anual (MA) e por período para cada posto (MP) do número de dias com precipitação entre os anos de 2003 e 2006 . Os números dos postos são os mesmos usados na confecção da Figura 1.

\begin{tabular}{|c|c|c|c|c|c|c|}
\hline Zona Ambiental & Posto/Ano & 2003 & 2004 & 2005 & 2006 & MIP \\
\hline \multirow{3}{*}{ Litoral } & Porto de Pedras & 256 & 265 & 231 & 220 & 243 \\
\hline & Maceió & 192 & 222 & 199 & 218 & 208 \\
\hline & Coruripe & 252 & 238 & 217 & 211 & 230 \\
\hline \multirow{5}{*}{ Zona da Mata } & Jundiá & 255 & 262 & 229 & 204 & 238 \\
\hline & Joaquim Gomes & 243 & 256 & 229 & 210 & 235 \\
\hline & São José da Laje & 227 & 231 & 196 & 180 & 209 \\
\hline & Boca da Mata & 240 & 227 & 207 & 204 & 220 \\
\hline & São Sebastião & 232 & 227 & 218 & 205 & 221 \\
\hline \multirow{2}{*}{ Baixo São Francisco } & Penedo & 240 & 229 & 220 & 206 & 224 \\
\hline & Porto Real do Colégio & 243 & 233 & 229 & 209 & 229 \\
\hline \multirow{2}{*}{ Agreste } & Palmeira dos Índios & 227 & 219 & 176 & 135 & 189 \\
\hline & Arapiraca & 227 & 213 & 210 & 206 & 214 \\
\hline \multirow{2}{*}{ Sertão do São Francisco } & Pão de Açúcar & 206 & 200 & 193 & 181 & 195 \\
\hline & Delmiro Gouveia & 121 & 123 & 163 & 146 & 138 \\
\hline \multirow{4}{*}{ Sertão } & Santana do Ipanema & 150 & 149 & 159 & 136 & 149 \\
\hline & Mata Grande & 134 & 137 & 164 & 154 & 147 \\
\hline & Água Branca & 129 & 120 & 163 & 144 & 139 \\
\hline & MA & 210 & 209 & 200 & 186 & 201 \\
\hline
\end{tabular}


A maior parte das precipitações observadas em Alagoas (iguais ou superiores a 5,0 $\mathrm{mm}$ ) esteve ligada aos cavados em baixos níveis e às POAs. Estas últimas foram encontradas em mais de $53 \%$ dos dias, já os cavados citados foram observados em quase $51 \%$ dos 314 dias que acumularam um valor de chuva igual ou superior a $5 \mathrm{~mm}$ (Tabela 2). A CJNEB teve papel importante em mais de $36 \%$ dos dias. Outros sistemas ligados às precipitações daquela magnitude não foram tão comuns, como os cavados em médios (13\%) e altos níveis (16\%), CCMs (7\%), ZCIT ou pulsos da ZCIT (11\%), EFs (10\%), VCANs (5\%), VCMNs (2\%), OLs (1\%) e anticiclones em médios e/ou altos níveis (11\%). A influência dos anticiclones em médios e/ ou altos níveis na formação das nuvens St no período chuvoso, foi discutida em Fedorova et al.(2008). Ainda a confluência (17\%) e difluência dos ventos (22\%) foram observadas. Várias combinações entre os sistemas meteorológicos estudados foram encontradas. Entre estas, a que mais se destacou foi a combinação entre POAS e cavados em baixos níveis (CES2),

Tabela 2 - Dias com Precipitação (DP) iguais ou superiores a 5,0 mm/ dia e sistemas associados a estas entre 2003 e 2006 para os 17 postos pluviométricos estudados. Legenda: CJNEB - Corrente de Jato do Nordeste Brasileiro; cavb - cavado em baixos níveis; cavm - cavado em médios níveis; cava - cavado em altos níveis; cvb - confluência dos ventos em baixos níveis; cvm - confluência dos ventos em médios níveis; dvm - difluência dos ventos em médios níveis; dva difluência dos ventos em altos níveis; $\mathrm{CCM}$ - Complexo Convectivo de Mesoescala; VCAN - Vórtice Ciclônico de Altos Níveis; VCMN - Vórtice Ciclônico de Médios Níveis; OL - Onda de Leste; POA - Perturbação Ondulatória dos Alísios; EF - Extremidade Frontal; ZCIT - Zona de Convergência Intertropical; PZCIT - Pulsos da ZCIT; antm - anticiclone em médios níveis; anta - anticiclone em altos níveis; CES1 - Combinação entre POAS e CJNEB; CES2 - Combinação entre POAS e cavb; CES3 - Combinação entre POAS, cavb e CJNEB; CES4 - Combinação entre POAS e sistemas diferentes de CJNEB e cavb; CES5 - Demais combinações entre os sistemas, exceto POAS.

\begin{tabular}{|c|c|c|c|}
\hline Sistema & DP & Sistema & DP \\
\hline PZCIT & 4 & $O L$ & 2 \\
\hline$E F$ & 1 & $C C M$ & 0 \\
\hline$c v b$ & 0 & cavb & 1 \\
\hline cvm & 1 & cavm & 2 \\
\hline CINEB & 2 & cava & 2 \\
\hline$d v a$ & 0 & ZCIT & 0 \\
\hline$d v m$ & 7 & CES1 & 14 \\
\hline anta & 0 & CES2 & 75 \\
\hline antm & 0 & CES3 & 40 \\
\hline POAS & 17 & CES4 & 39 \\
\hline VCAN & 1 & CES5 & 105 \\
\hline VCMN & 1 & & \\
\hline
\end{tabular}

observada em 75 dos 314 dias cujo valor de precipitação diário se igualou ou superou os $5 \mathrm{~mm}$ (Tabela 2).

É necessário ressaltar que os sistemas citados interagiram entre si em grande parte dos dias. Dessa forma, as porcentagens mencionadas referem-se a atuação de cada sistema, independente de sua ligação ou não com outro(s) sistema(s).

\subsection{Frequência das Precipitações Intensas e Sistemas Meteorológicos Associados}

A análise da frequência dos casos que envolveram precipitações intensas em Alagoas resultou no número de vinte $\mathrm{e}$ um eventos extremos. A Tabela 3 aponta os casos de precipitação intensa mês a mês entre os anos de 2003 e 2006, assim como suas médias e totais para cada mês e ano. Sua maior fração se deu no Grupo B, especialmente na Zona da Mata, que esteve envolvida em quase metade dos casos.

A média de casos com precipitações intensas resultou no número de 5,25 casos por ano, sendo que, em sua grande maioria, tais casos foram reparados no mês de junho, havendo registro de pelo menos um evento extremo de intensa precipitação por ano naquele mês no período estudado.

Nos meses de janeiro e maio foram registrados quatro casos, individualmente, perdendo para junho apenas por um evento. O mês de janeiro não está incluído no grupo de meses que constitui o período chuvoso alagoano, o que deixa claro que os casos de precipitação intensa naquele Estado também ocorrem no período seco. Contudo, não foram registradas precipitações de forte intensidade nos meses de julho e agosto, diferente do que se observou em julho/agosto de 2000 (Molion et al., 2002b). Em outras palavras, só o fato de ser um mês do período chuvoso não implica a ocorrência de algum evento extremo.

As precipitações com valores iguais ou acima de 100 mm diários, observadas no Grupo A nos anos pesquisados, somaram apenas 3 casos. $\mathrm{O}$ evento mais expressivo dentre tais eventos foi observado no dia $1^{\circ}$ de junho de 2004 , onde o acumulado de chuva em 24 horas alcançou mais de $180 \mathrm{~mm}$ na cidade de Maceió (Calheiros et al., 2006). Naquele mesmo mês, no dia 14, fora observado um valor de $102 \mathrm{~mm}$ naquele local. De acordo com a Universidade Federal de Campina Grande (UFCG, 2008) o volume de precipitação esperado para o mês de junho em Maceió é de $243 \mathrm{~mm}$, conforme a média de precipitação do período de 1911-1990. Ou seja, em apenas dois dias choveu mais do que o volume normal esperado para aquele mês inteiro. Um terceiro dia com registro de precipitação intensa foi 16 de junho de 2003, onde foram acumulados $146 \mathrm{~mm}$ na capital de Alagoas. Todos os casos de precipitação intensa no Grupo A ocorreram no período chuvoso. Apenas em um caso do Grupo B, o acumulado diário de precipitação alcançou um valor superior a $100 \mathrm{~mm}$. 
Tabela 3 - Frequência dos Casos de Precipitação Intensa em Alagoas no período de 2003 a 2006.

\begin{tabular}{l|l|l|l|l|c|c}
\hline Mês/Ano & $\mathbf{2 0 0 3}$ & $\mathbf{2 0 0 4}$ & $\mathbf{2 0 0 5}$ & $\mathbf{2 0 0 6}$ & Total Mensal & Média \\
\hline Jan & 1 & 2 & 1 & 0 & $\mathbf{4}$ & 1,00 \\
\hline Fev & 0 & 0 & 0 & 0 & 0 & 0,00 \\
\hline Mar & 0 & 0 & 0 & 1 & 1 & 0,25 \\
\hline Abr & 0 & 1 & 0 & 2 & $\mathbf{3}$ & 0,75 \\
\hline Mai & 0 & 1 & 1 & 2 & $\mathbf{4}$ & 1,00 \\
\hline Jun & 1 & 2 & 1 & 1 & $\mathbf{5}$ & 1,25 \\
\hline Jul & 0 & 0 & 0 & 0 & 0 & 0,00 \\
\hline Ago & 0 & 0 & 0 & 0 & 0 & 0,00 \\
\hline Set & 1 & 0 & 0 & 1 & 2 & 0,50 \\
\hline Out & 1 & 0 & 0 & 0 & 1 & 0,25 \\
\hline Nov & 0 & 0 & 0 & 0 & 0 & 0,00 \\
\hline Dez & 0 & 0 & 1 & 0 & 1 & 0,25 \\
\hline Total Anual & 4 & 6 & 4 & 7 & $\mathbf{2 1}$ & $\mathbf{5 , 2 5}$ \\
\hline
\end{tabular}

Em vários dias ocorreram precipitações que acumularam $60 \mathrm{~mm}$ ou mais em Alagoas, especialmente no Litoral (Grupo A). Contudo, em apenas 21 dias houve registro de tais valores de precipitação no Grupo B. Nesse grupo, dez casos de precipitação intensa ocorreram no período chuvoso, ou seja, mais de $70 \%$ do total de casos, já que os demais casos apareceram na época seca e, no geral, com valores diários de precipitação e número de dias com precipitação por caso, menores do que aqueles contabilizados no período úmido.

Foram observados dezesseis dias com registro de precipitações que acumularam valores iguais ou maiores que 40 $\mathrm{mm}$ no Grupo C. Dentre os casos de precipitações intensas, o valor máximo de precipitação em 24 horas encontrado foi de 82 mm no Sertão, e mínimo de 40 mm no Sertão do São Francisco. O Grupo C presenciou sete dos seus treze casos de precipitação intensa no período seco das Alagoas, ou seja, os eventos de precipitação expressiva ocorreram em qualquer época do ano.
O número máximo de casos constatados foi observado no mês de janeiro, com quatro episódios de precipitação intensa.

A Tabela 4 foi montada com a finalidade de expor os sistemas associados às precipitações intensas presentes nos 21 (vinte e um) casos observados no Estado de Alagoas durante os quatro anos de estudo (2003 a 2006).

Diversos sistemas sinóticos e de mesoescala participaram nos casos de chuvas extremas em Alagoas. A CJNEB deu suporte aos movimentos ascendentes do ar, facilitando a formação de nuvens e chuvas intensas em $38 \%$ dos casos. As extremidades das frentes frias (EF) estiveram associadas a mais de $28 \%$ dos eventos. Em apenas 1/4 dos casos aquelas extremidades não produziram nuvens do tipo $\mathrm{Cb}$; nos demais eventos, aquele tipo de nuvem esteve ligado a elas, causando fortes chuvas em Alagoas.

Apenas em um caso, um VCAN foi corresponsável pelas precipitações intensas observadas em Alagoas, atuando com sua borda oeste naquele Estado. Também em um só evento a circulação da Alta da Bolívia (AB), com sua parte central posicionada na fronteira entre as regiões Sudeste, Centro-Oeste e Nordeste do Brasil, esteve ligada à ocorrência de precipitações intensas sobre Alagoas. Aquele sistema gerou uma grande área de difluência dos ventos em altos níveis, o que deu suporte a formação de CCMs sobre o NEB. Em mais da metade dos casos, os aglomerados de $\mathrm{Cbs}(\mathrm{aCb})$ (por vezes CCMs) foram vistos, com aparição em todos os eventos que envolveram o Sertão, sendo que não apareceram em nenhum caso do Grupo A, apesar de terem sido observados em alguns casos de chuvas não muito intensas. As Ondas de Leste (OL) estiveram presentes em apenas um dos eventos extremos. Elas apareceram em diversos outros casos de chuvas moderadas e fracas, porém sem apresentar sua forma clássica. Os pulsos associados à ZCIT (PZCIT) estiveram ligados a $14 \%$ dos eventos excepcionais. As POAs estiveram relacionadas a $28 \%$ dos casos de precipitação intensa, gerando

Tabela 4 - Sistemas meteorológicos associados aos casos de precipitação intensa ocorridos em Alagoas entre os anos de 2003 e 2006 e Grupos Afetados (GA). Legenda: aCb - aglomerado de cumulonimbos.

\begin{tabular}{r|l|l}
\hline \multicolumn{1}{l|}{ Período } & Sistema (s) & GA \\
\hline 28/1/2003 & CCM & C \\
\hline $15 / 6 / 2003$ & OL/CJNEB & A e B \\
\hline $4-5 / 9 / 2003$ & EF/POA/CJNEB & B \\
\hline $17 / 10 / 2003$ & EF & B \\
\hline $12 / 1 / 2004$ & EF/CCM/CJNEB & $\mathrm{C}$ \\
\hline $18 / 1 / 2004$ & EF/CCM & B e C \\
\hline $13 / 4 / 2004$ & $\mathrm{CCM}$ & $\mathrm{B} \mathrm{e} \mathrm{C}$ \\
\hline $12 / 5 / 2004$ & $\mathrm{aCb}$ & $\mathrm{C}$ \\
\hline $1-2 / 6 / 2004$ & $\mathrm{aCb} / \mathrm{POA}$ & $\mathrm{A}, \mathrm{B} \mathrm{e} \mathrm{C}$ \\
\hline $14-17 / 6 / 2004$ & $\mathrm{aCb} / \mathrm{POA} / \mathrm{CJNEB}$ & $\mathrm{A} \mathrm{e} \mathrm{B}$ \\
\hline $13-14 / 1 / 2005$ & $\mathrm{CCM} / \mathrm{VCAN}$ & $\mathrm{C}$ \\
\hline
\end{tabular}

\begin{tabular}{r|l|l}
\hline \multicolumn{1}{l|}{ Período } & Sistema (s) & GA \\
\hline $2-4 / 5 / 2005$ & $\mathrm{EF} / \mathrm{aCb}$ & $\mathrm{B} \mathrm{e} \mathrm{C}$ \\
\hline $13-14 / 6 / 2005$ & $\mathrm{POA}$ & $\mathrm{B}$ \\
\hline $5 / 12 / 2005$ & $\mathrm{EF} / \mathrm{CCM} / \mathrm{CJNEB}$ & $\mathrm{C}$ \\
\hline $23-24 / 3 / 2006$ & $\mathrm{CCM} / \mathrm{PZCIT} / \mathrm{CJNEB}$ & $\mathrm{C}$ \\
\hline $19-20 / 4 / 2006$ & $\mathrm{aCb} / \mathrm{PZCIT}$ & $\mathrm{C}$ \\
\hline $25 / 4 / 2006$ & $\mathrm{aCb} / \mathrm{CJNEB}$ & $\mathrm{B}$ \\
\hline $30 / 4-2 / 5 / 2006$ & $\mathrm{aCb} / \mathrm{PZCIT}$ & $\mathrm{B} \mathrm{e} \mathrm{C}$ \\
\hline $15 / 5 / 2006$ & $\mathrm{EF} / \mathrm{CJNEB}$ & $\mathrm{B}$ \\
\hline $17 / 6 / 2006$ & $\mathrm{POA}$ & $\mathrm{B}$ \\
\hline $9-10 / 9 / 2006$ & $\mathrm{POA}$ & $\mathrm{B} \mathrm{e} \mathrm{C}$ \\
\hline & & \\
\hline & &
\end{tabular}


nebulosidade convectiva considerável ao entrarem em contato com a costa leste do NEB.

\subsection{Análise Sinótica dos Casos com Registro de Precipitações Intensas no Estado de Alagoas}

Muitos estudos recentes a respeito de eventos extremos de precipitação em Alagoas foram publicados, como o caso de junho de 2001 (Costa et. al., 2004), janeiro de 2002 (Salvador, 2004a, Molion et al., 2002a), março de 2003 (Rodrigues, 2006), janeiro de 2004 (Levit et al., 2004, Salvador, 2004b, Molion e Calheiros et. al., 2004), junho de 2004 (Calheiros et al., 2006), fevereiro de 2008 (Brito et. al, 2008). Esses estudos mostraram os mecanismos associados às precipitações intensas em Alagoas, tais como a forte convergência de umidade do Oceano para o continente, distúrbios ondulatórios de leste e sua interação com restos frontais, Vórtices Ciclônicos de Altos Níveis, além da anomalia positiva de TSM no Atlântico Sul (Mattos e Reis, 2004). Em sua maioria, esses trabalhos se limitam ao estudo dos fatores que contribuíram para o desenvolvimento dos sistemas que resultaram em precipitações intensas ocorridas no litoral ou parte leste do Estado. Além disso, muitos desses estudos focalizaram os eventos ocorridos no período chuvoso. Por estas razões, será discutido aqui um dos eventos extremos que se manifestou no oeste de Alagoas, região semiárida do Estado, no período seco, apesar dos sistemas sinóticos ligados a tal evento não terem sido aqueles mais observados no período de estudo.

Nesse caso, observado no mês de janeiro de 2005, os sistemas que provocaram precipitação intensa no Estado de Alagoas, assim como os mecanismos associados à sua formação, foram identificados.

\section{Caso dos Dias 13 e 14 de Janeiro de 2005}

Esse caso foi selecionado por se adequar ao padrão estipulado nesse estudo, onde as precipitações acima de $40 \mathrm{~mm}$ em 24 horas são classificadas como intensas no Grupo C. Tal escolha também se deve ao fato de que, poucos estudos têm procurado as causas das precipitações intensas nessa região do Estado, uma vez que estas não são comuns, ao inverso do que ocorre no leste das Alagoas, onde precipitações intensas são mais frequentes e os sistemas sinóticos ligados a estas têm sido discutidos. Entre os dias 13 e 14 de janeiro de 2005 várias cidades de Sergipe e do oeste alagoano foram atingidas por chuvas fortes acompanhadas de rajadas de vento e várias descargas elétricas.

De acordo com o PROCLIMA, em Pão de Açúcar e Palestina foram registrados, $49 \mathrm{e} 51 \mathrm{~mm}$ de chuva, respectivamente, entre a noite do dia 13 e a madrugada do dia 14. Acumulados superiores a $30 \mathrm{~mm}$ foram registrados em vários outros municípios do oeste de Alagoas (Figura 3).
No campo de linhas de corrente e magnitude do vento em $1000 \mathrm{hPa}$ das $18 \mathrm{UTC}$ do dia 13, nota-se a confluência dos ventos em baixos níveis, desde o norte da Bahia até o Sudeste do Brasil (Figura 4a). Tal confluência, ligada à extremidade frontal no Oceano Atlântico, é intensificada e se aproxima de Alagoas no horário das 00UTC do dia seguinte (14 de janeiro) às 00UTC (Figura $4 \mathrm{~b}$ ). Também pôde-se observar uma crista, a qual se deslocou para leste. Na altura relativa a $850 \mathrm{hPa}$, percebe-se que a confluência dos ventos se estendia desde a superfície. A mesma se deslocou para leste, acompanhando o fluxo à superfície. Entre às $18 \mathrm{UTC}$ do dia $13 \mathrm{e}$ às $00 \mathrm{UTC}$ do dia 14 , vê-se o enfraquecimento da crista localizada a norte da área de confluência no primeiro horário citado (Figura 4).

O reflexo dos mecanismos observados em baixos níveis ainda fez-se sentir em $700 \mathrm{hPa}$, tanto que a confluência sobre o Estado da Bahia ainda pode ser vista, no entanto mais deslocada para Sul em relação aos níveis baixos (Figura 4a). Esse fato indica que a extremidade frontal se aprofundava até médios níveis, mostrando ser bem intensa, mesmo situando-se em latitudes tropicais. Analogamente à análise em baixos níveis, especialmente no que se refere à altura isobárica de $850 \mathrm{hPa}$, a crista observada entre as 18 UTC do dia 13 e 00UTC do dia 14 , ficou bem menos intensa na passagem dessas seis horas, o que coincide exatamente com a evolução do sistema observado neste caso de precipitações intensas.

No nível de $500 \mathrm{hPa}$, pôde-se verificar a existência de um cavado bem definido partindo desde o sudeste até o leste de

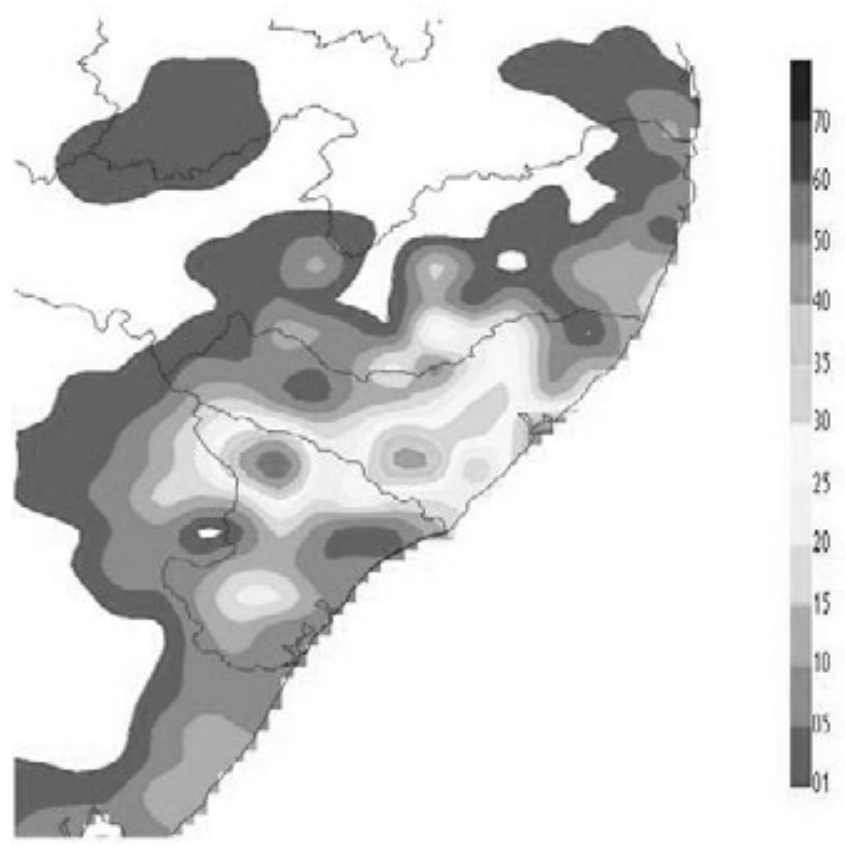

Figura 3 - Precipitação acumulada entre a noite do dia 13 e inicio do dia 14 de janeiro de 2005. Fonte: CPTEC/Clima. 


\section{3-01-2005 (1000-700 hPa)}
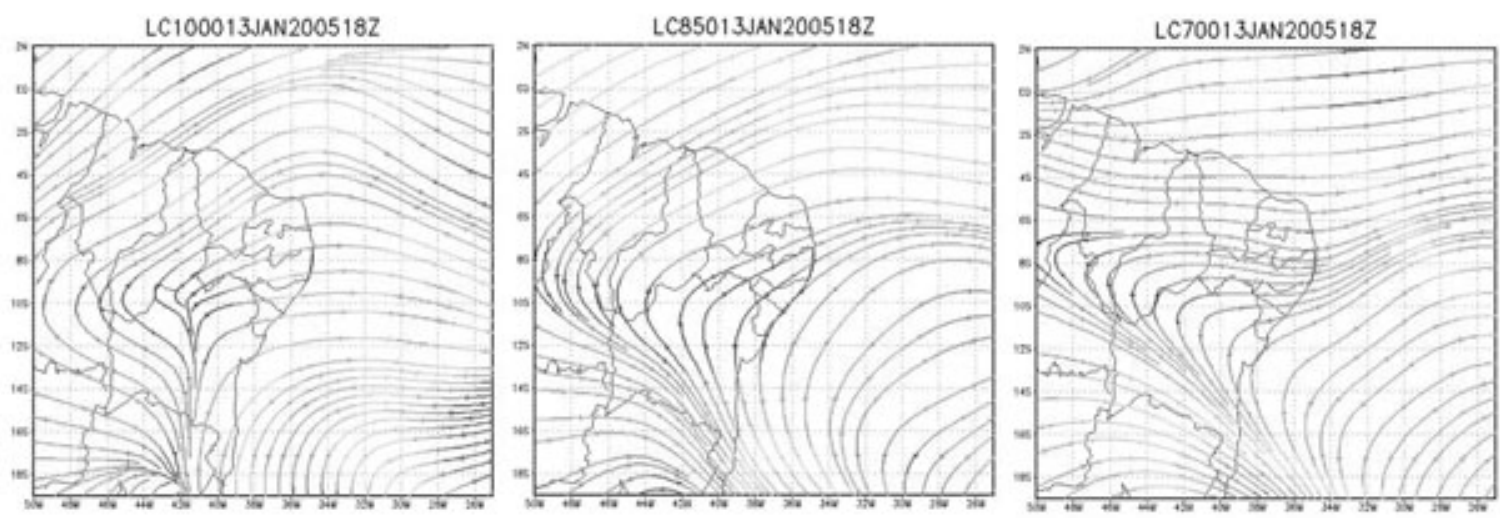

A

\section{4-01-2005 (1000-700 hPa)}
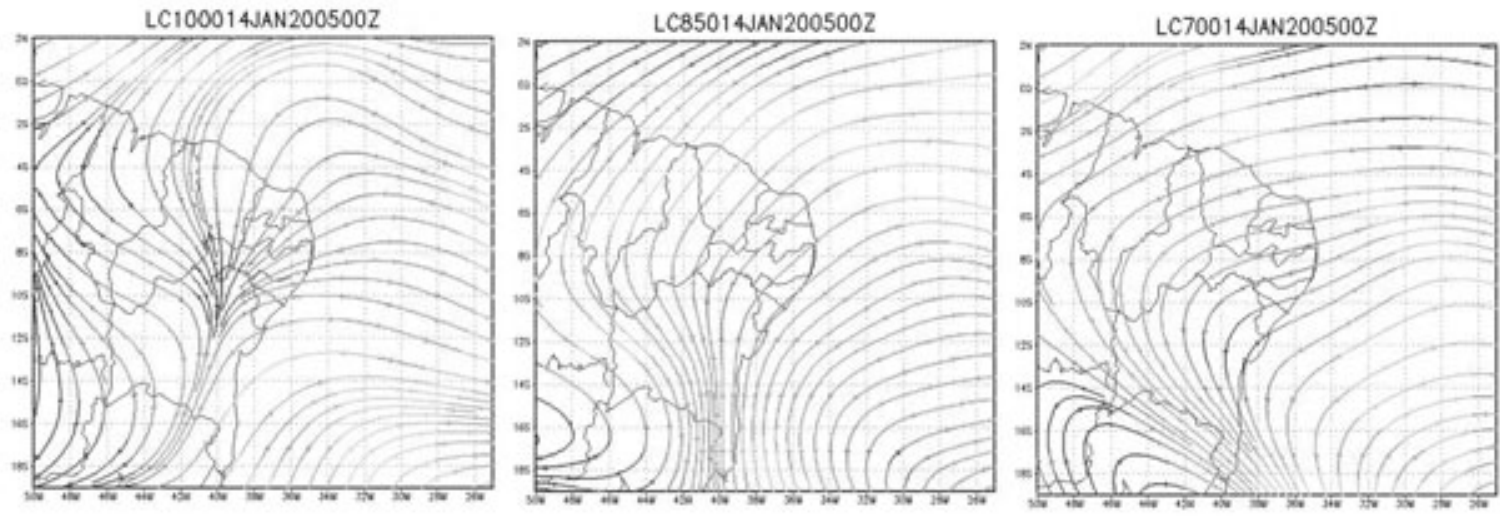

Figura 4 - Linhas de corrente referentes às $18 \mathrm{UTC}$ do dia 13 (a) e às 00UTC do dia14 (b) de janeiro de 2005 nos níveis de 1000,850 e 700 hPa (da esquerda para a direita).

Pernambuco entre dois anticiclones no dia 13 às 18UTC, assim como uma área de divergência do vento na altura da Paraíba (Figura 5a). Na imagem do dia 14 de janeiro (Figura 5b) o cavado se enfraquece e a divergência fica mais visível do que na imagem anterior. $\mathrm{O}$ anticiclone observado na imagem das 18UTC sobre o oceano deu lugar a uma crista.

Em altos níveis, especificamente em $300 \mathrm{hPa}$, um VCAN fora observado com seu centro localizado no litoral alagoano às $18 \mathrm{UTC}$ do dia 13 (Figura 5a). No mesmo horário do dia seguinte, aquele sistema se deslocou para nordeste, deixando sua borda oeste sobre o Estado de Alagoas, borda esta geralmente associada à forte convecção, ao mesmo tempo em que se fechou uma alta pressão a sul desse sistema (Figura $5 b$ ). Em ambos horários um cavado atuava entre o nordeste mineiro, sul baiano e norte do Espírito Santo, se adentrando na Bahia no horário das 00UTC do dia 14 (Figura 5b). Entre aqueles dois sistemas, havia uma crista, que deu suporte à formação de um anticiclone às 00UTC do dia 14 . Em $200 \mathrm{hPa}$, às 18 UTC do dia 13, é observada a presença de um VCAN cujo centro encontrava-se nas proximidades das coordenadas de $9^{\circ} \mathrm{S} \mathrm{e} 32^{\circ} \mathrm{W}$, logo a leste de Alagoas e Pernambuco, assim como uma crista, a qual estendia-se da Bahia em direção ao Oceano Atlântico. Um cavado também podia ser visto entre o norte do Espírito Santo, sul da Bahia e nordeste mineiro, um provável aprofundamento do cavado observado em 300 e $500 \mathrm{hPa}$, onde o mesmo estava mais intenso.

Aqueles dois sistemas também foram vistos na imagem das 00UTC do dia posterior (14 de janeiro), porém um pouco mais afastados para leste (Figura $5 b$ ). Nas duas imagens foram notados ventos fortes entre o ramo oeste do VCAN e ventos difluentes no norte do NEB, em outras palavras, uma CJNEB. Essa característica deu suporte ao sistema que culminou na queda de chuvas fortes em Alagoas. Em relação ao nível de 300 $\mathrm{hPa}$, o VCAN esteve posicionado um pouco mais para leste, o que evidencia a orientação da inclinação de seu eixo.

Os movimentos verticais, observados através da seção vertical confeccionada para as 00UTC do dia 14 de janeiro de 2005 ( $21 \mathrm{~h}$ local do dia 13), mostrou a existência de movimentos verticais ascendentes do ar na área de formação do CCM, o que resultou em fortes chuvas no sertão alagoano (Figura 6). 
13-01-2005 (500-200 hPa)
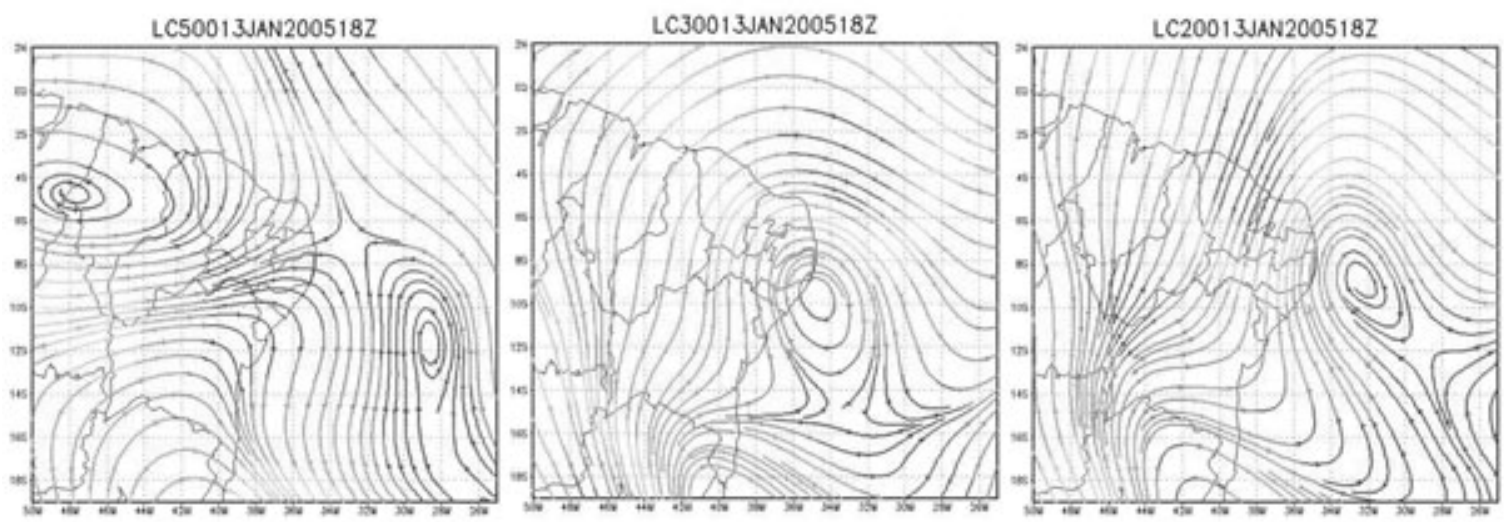

A

14-01-2005 (500-200 hPa)
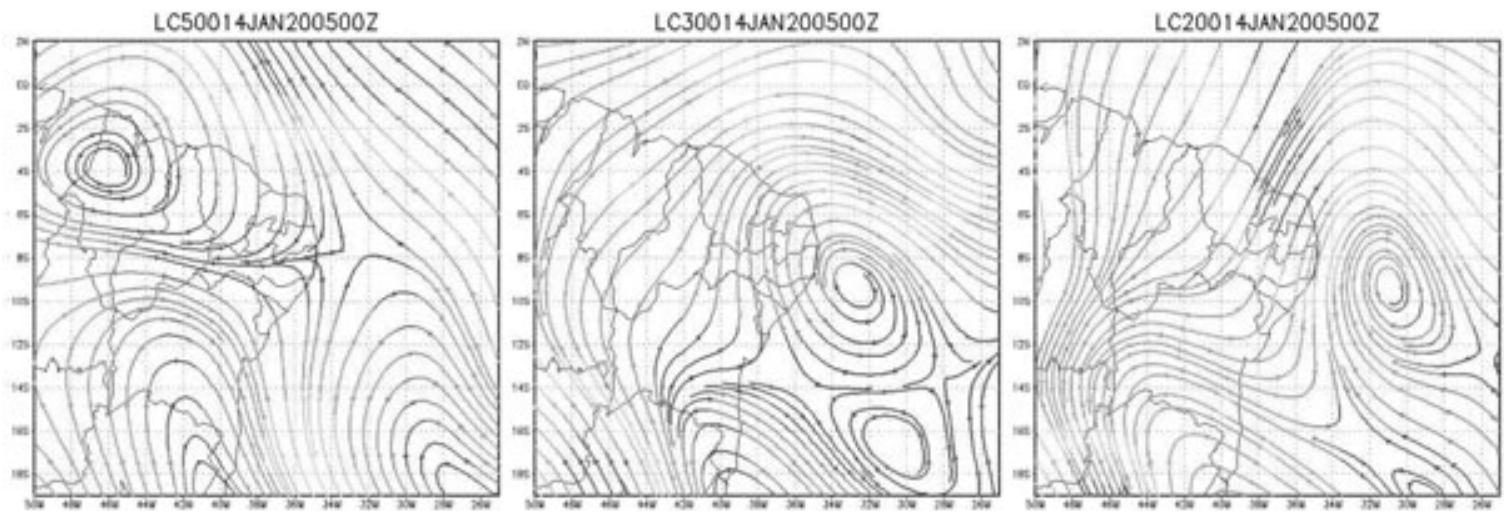

Figura 5 - Linhas de corrente referentes às $18 \mathrm{UTC}$ do dia 13 (a) e às 00UTC do dia14 (b) de janeiro de 2005 nos níveis de 500, 300 e 200 hPa (da esquerda para a direita).

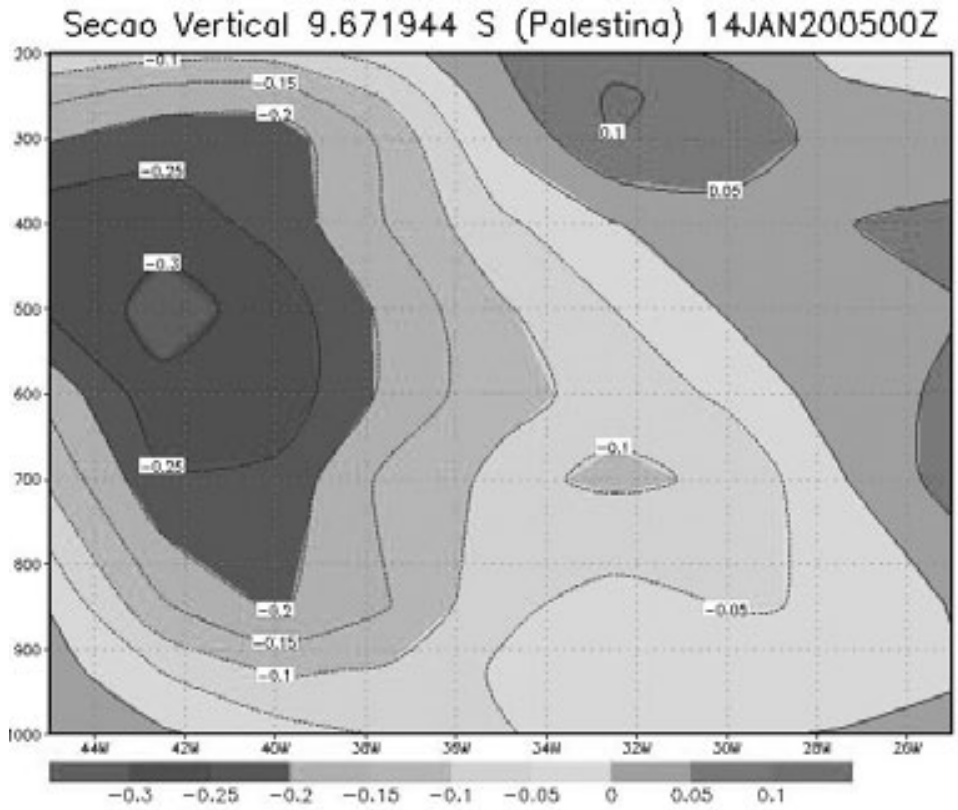

Figura 6 - Secção Omega (hPa/s) na latitude de Palestina-AL as 00UTC do dia 14 de janeiro de 2005. 
No recorte da imagem do satélite GOES-12 do dia 13 de janeiro de 2005 às 20:45UTC, notou-se uma grande faixa de nebulosidade atuando no Brasil, especialmente em sua porção centro-norte, sendo que tais nuvens estiveram associadas a CJNEB, presente na borda oeste um VCAN, e à extremidade de um Sistema Frontal no Oceano Atlântico Sul (Figura 7a), conforme já visto através do campo de linhas de corrente anteriormente. No recorte da imagem do horário das 23:45UTC daquele mesmo dia, pôde-se observar o aparecimento de um CCM junto ao centro-leste do NEB devido à intensificação da borda oeste do VCAN. Outro fator que contribuiu na formação do CCM foi a forte confluência dos ventos em baixos níveis associada à extremidade da Zona Frontal no Oceano, inclusive atingindo o oeste de Alagoas.

Foram construídos os perfis verticais simulados para o município mais atingido pelo evento extremo de precipitações em Alagoas, Palestina $\left(-9,671944^{\circ}\right.$ latitude; $-37,329167^{\circ}$ longitude), relativos ao dia 14 de janeiro de 2005, às 00UTC, horário de desenvolvimento máximo do fenômeno adverso. Um perfil teve como dados de construção a análise feita pelo Modelo Regional ETA, adaptado para Alagoas numa resolução

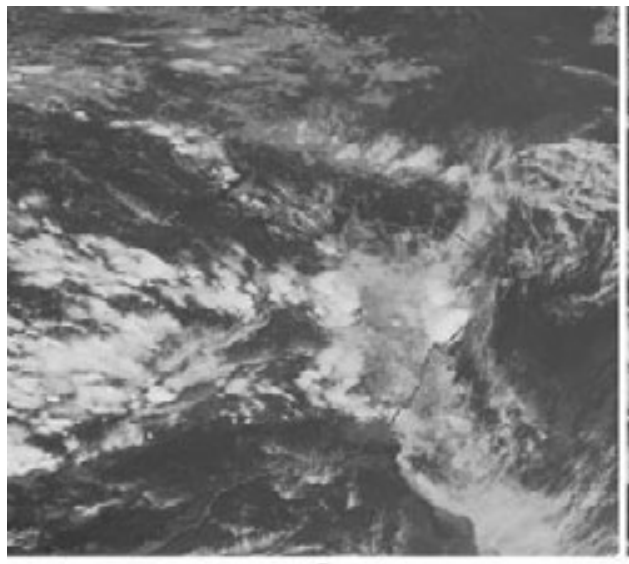

a

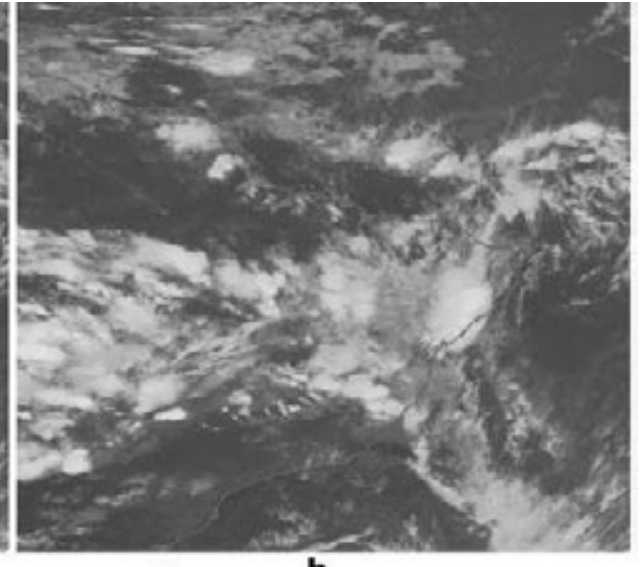

b

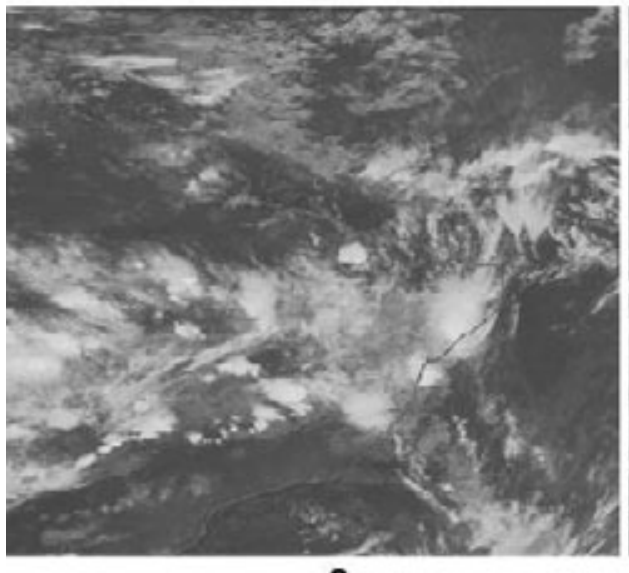

c

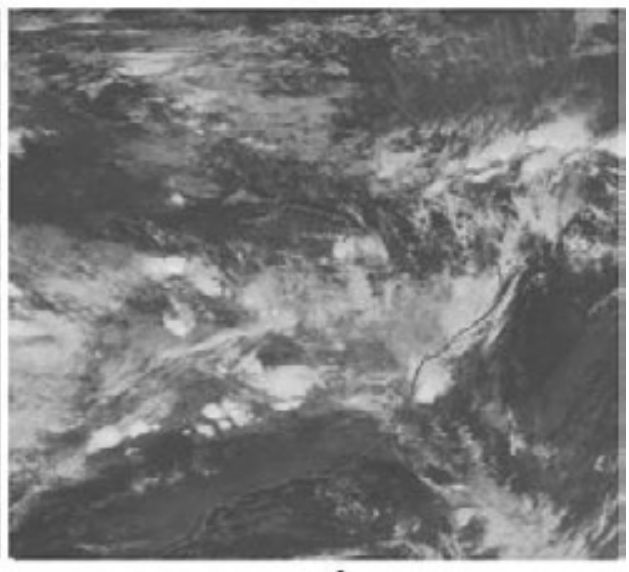

d de 15x15 km pelo Núcleo de Meteorologia da SEMARH/AL, tendo como condição de entrada os dados do modelo Global do NCEP/NOAA (GFS - Global Forecast System), usados na composição de um segundo perfil vertical.

O perfil, referente ao modelo ETA, indicou que a atmosfera estivera seca entre 650 e $550 \mathrm{hPa}$ e acima de 400 hPa. Entre 800 e $700 \mathrm{hPa}$ indicou umedecimento. Contudo, em níveis mais baixos, não foi exibida uma atmosfera muito úmida (Figura 8a). Os dados de reanálise do modelo GFS resultaram num perfil similar ao obtido pelo ETA. A diferença ficou na área de umedecimento, entre 925 e $850 \mathrm{hPa}$ e acima de 350 $\mathrm{hPa}$ (Figura 8b).

ACAPE + (Energia Potencial Disponível para Convecção) calculada pelos dados do ETA para o horário das 00UTC do dia 14 de janeiro de 2005 resultou em $380 \mathrm{~J} / \mathrm{Kg}$, ou seja, não haveria disponibilidade de energia de instabilidade na atmosfera o suficiente para o desenvolvimento de convecção profunda naquela área. $\mathrm{O}$ valor encontrado para a $\mathrm{CAPE}+$ via dados de reanálise do NCEP, foi de $702 \mathrm{~J} / \mathrm{Kg}$, ou seja, pouco instável.

Apesar do valor da CAPE+ ter sido baixo quando calculado através dos dados do modelo ETA, os índices de

Figura 7 - Imagens do satélite GOES-12 no canal infravermelho às 20:45UTC (a) e 23:45UTC (b) do dia 13 e às 02:45UTC (c) e 05:45UTC (d) do dia 14 janeiro de 2005 .

Fonte: SSEC 


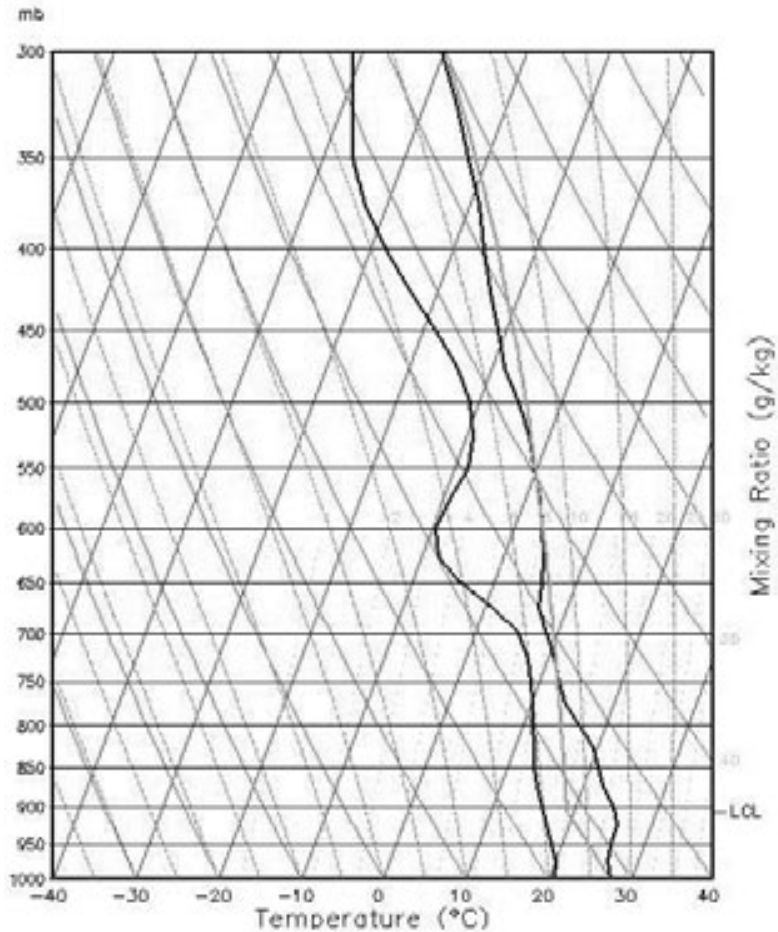

(a)

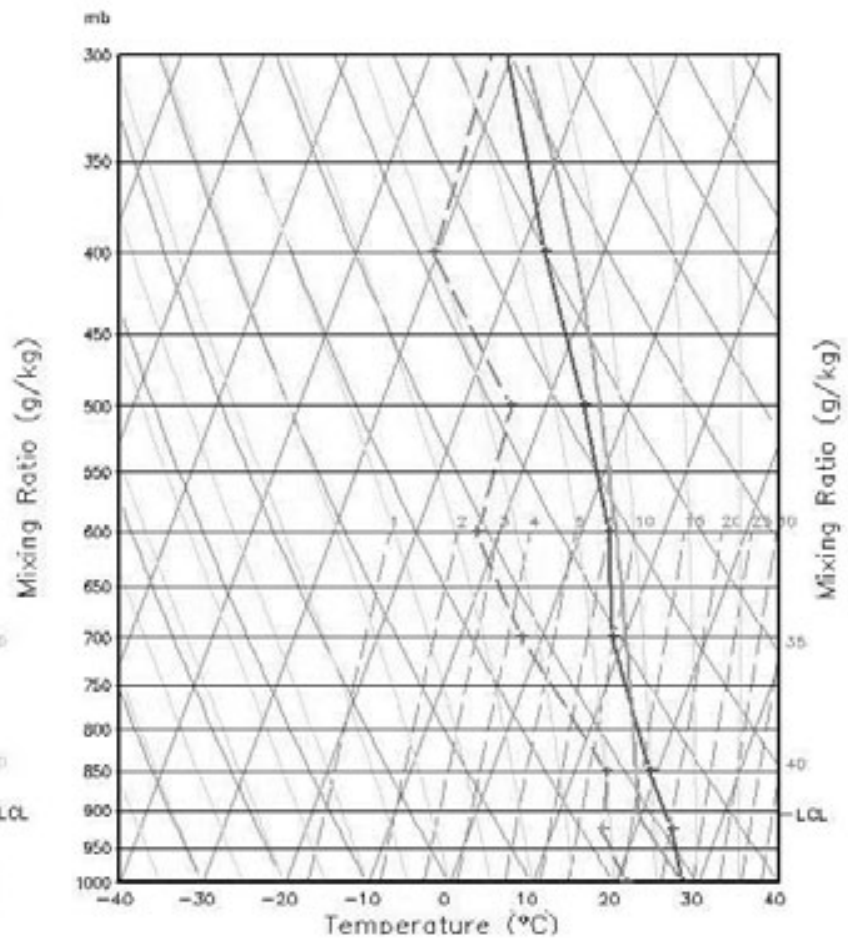

(b)

Figura 8 - Perfis verticais simulados em Palestina pelos dados do modelo ETA (a) e GFS (b) para as 00 UTC do dia 14 de janeiro de 2005.

instabilidade K e TT concordaram no aspecto de instabilidade atmosférica observada naquele dia, com valores 32 e 44, nesta ordem. Apenas o índice LI discordou com a observação meteorológica, igualando-se a -1. Quando utilizados os dados de reanálise do NCEP, obtiveram-se valores de 27, 43 e -2 para o K, TT e LI respectivamente, valores que se referem a uma atmosfera com instabilidade fraca.

Em suma, os resultados obtidos através da construção dos perfis verticais para o local mais afetado pelo evento severo não condizem com a realidade observada no local. Ocorreu queda de granizo, muitas descargas elétricas, rajadas de vento e chuva forte nesse caso.

Através das considerações realizadas por meio da análise cuidadosa dos vários campos meteorológicos, pode-se afirmar que o evento de precipitações intensas ocorrido entre os dias 13 e 14 de janeiro de 2005, no oeste de Alagoas, foi resultado do alinhamento entre vários mecanismos. Esses geraram precipitações intensas por resultarem na formação de um Complexo Convectivo de Mesoescala (CCM) entre a noite do dia 13 e a madrugada do dia 14.

Entre tais mecanismos, destacaram-se a confluência dos ventos em baixos níveis, processo causador de forte convecção, presença de um cavado em médios níveis, atividade da borda oeste de um VCAN, influência da extremidade de uma Zona Frontal no Oceano Atlântico e a presença de um VCMN, o qual se prolongou durante algumas horas até altos níveis, sendo de extrema importância nesse caso, vista sua circulação, que proporcionou, junto a um anticiclone naquele mesmo nível sobre o norte do NEB, a difluência dos ventos em médios níveis sobre a região afetada pelo CCM, organizando os movimentos ascendentes do ar. Naquela ocasião choveu mais do que o esperado para o mês inteiro de janeiro, que é de aproximadamente $35 \mathrm{~mm}$.

\section{CONCLUSÕES}

A análise dos casos de precipitações intensas em Alagoas deixou claro que esse fenômeno extremo ocorreu tanto no período chuvoso, como no seco. O mês de junho registrou um número máximo de casos, que somaram 5 dos 12 casos observados no período chuvoso. Na época seca, foram registrados 9 casos, concentrando-se 4 deles só no mês de janeiro. É digno de nota que, o Grupo $\mathrm{C}$ foi afetado pelas chuvas intensas em todos os casos que ocorreram nesse mês. Não ocorreram casos de precipitação intensa nos meses de fevereiro, julho, agosto e novembro. O grupo mais castigado pelos casos de precipitação intensa foi o Grupo B, encontrado em $66,6 \%$ dos eventos extremos. A média de casos por ano obtida foi de 5,25, de um total de 21 casos constatados entre 2003 e 2006. Apenas um caso envolveu os três grupos.

Os cavados em baixos níveis foram identificados em quase $51 \%$ dos eventos de chuvas iguais ou superiores a $5 \mathrm{~mm}$ 
diários, precipitações minimamente significativas. A CJNEB esteve presente em cerca de $36 \%$ dos casos, muitas vezes dando suporte às POAs ( $53 \%$ dos casos), observadas em níveis baixos, ou simplesmente à configuração de brisa, intensificada pela circulação gerada pela ASAS. Os ventos Alísios, em grande parte das vezes associados a uma circulação ciclônica discreta, e os cavados em médios e altos níveis, foram os responsáveis por 13 e 16\% das precipitações, respectivamente. A difluência e confluência dos ventos estiveram presentes em 17 e $22 \%$ dos casos de precipitações de intensidade fraca ou moderada. Os demais sistemas foram observados em menos de $10 \%$ dos casos, cada.

Diferentes sistemas sinóticos e de mesoescala estiveram associados aos casos de precipitações intensas em Alagoas. A CJNEB organizou os movimentos ascendentes do ar, facilitando a formação de nuvens e chuvas intensas em um pouco mais de $38 \%$ dos casos extremos. As extremidades das frentes frias estiveram associadas a quase $28 \%$ dos eventos, em alguns casos, provocando chuvas de moderada a forte intensidade durante vários dias consecutivos. Em mais de $70 \%$ dos casos excepcionais, os aglomerados de $\mathrm{Cbs}$, em alguns momentos CCMs, foram observados aparecendo em $90,47 \%$ dos eventos que envolveram o Grupo C. As POAs apareceram em $28 \%$ dos eventos. Outros sistemas, tais como VCAN, OL e AB, estiveram relacionados a menos de $5 \%$ dos casos, cada um.

Os mecanismos que mais contribuíram na origem e na manutenção dos sistemas, associados às precipitações intensas, foram: 1) a difluência do vento em médios e altos níveis, presente em torno de $47 \%$ dos casos e 2) os cavados em baixos níveis, observados em quase $60 \%$ dos casos. A confluência dos ventos em baixos e médios níveis apareceu em quase $33 \%$ dos eventos.

No período examinado neste trabalho (2003 a 2006), percebeu-se que diferentes sistemas sinóticos estiveram associados a precipitações intensas em Alagoas. A CJNEB, as POAs e as EFs foram os maiores contribuidores no que se diz respeito às precipitações intensas, sendo os dois primeiros também os sistemas prevalecentes nos casos de precipitações de intensidade moderada e fraca. No entanto, tais sistemas sempre estão ligados a mecanismos-chave no momento de gerar condições para precipitações de grandes proporções. Por exemplo, geralmente, a CJNEB não desenvolveria nebulosidade capaz de produzir precipitações intensas. No entanto, se abaixo dela as condições forem favoráveis, por exemplo, se houver um cavado, uma POA ou uma extremidade frontal, as circulações transversais da CJNEB organizarão os movimentos verticais, dando suporte àqueles sistemas. De maneira similar, uma extremidade frontal, que em muitos casos já avança aos restos pelo leste do NEB, só organizará bandas de precipitação intensa se existir algum meio para isso, como a confluência entre os ventos Alísios e os ventos de sul que, geralmente, acompanham a alta pós-frontal associada àquela frente.
Como pode-se notar, a interação dos processos atmosféricos, não só em Alagoas, mas em boa parte do NEB, constitui um problema na identificação dos sistemas sinóticos naquela área, que apresentam características dúbias na maioria dos casos, especialmente em se tratando de sistemas causadores de precipitações intensas. Esse tipo de problema pode acarretar em grandes erros de previsão do tempo, o que pode ter como consequência, a perda de bens materiais e até mesmo de vidas humanas, como na tragédia do ano $2000 \mathrm{em}$ Alagoas, quando foram vitimadas 56 pessoas, em detrimento das chuvas excepcionais. Em suma, a identificação dos sistemas meteorológicos que podem se alinhar sobre o Estado melhorará a previsão do tempo naquela região, dando uma ideia dos efeitos resultantes da relação entre aqueles sistemas.

A interação entre os sistemas sinóticos atuantes nas Alagoas, geradores de precipitações intensas, será mais bem compreendida fazendo-se uso de uma série maior de dados meteorológicos convencionais e, de forma especial, um banco de dados mais longo de imagens de satélite em vários canais, o que facilitará a identificação daqueles sistemas e como estão ligados entre si. Algo realmente imprescindível já que, muitas vezes, os mecanismos associados à formação e manutenção daqueles sistemas não são bem visualizados via campos meteorológicos, devido à sua resolução espacial.

\section{AGRADECIMENTOS}

Os autores agradecem à Fundação de Amparo à Pesquisa do Estado de Alagoas (FAPEAL) e ao Conselho Nacional de Desenvolvimento Científico e Tecnológico (CNPq) pela concessão de bolsas durante a composição deste trabalho.

\section{REFERÊNCIAS BIBLIOGRÁFICAS}

ALVES, J. M.; FERREIRA, F. F.; CAMPOS, J. N. B.; SOUZA, E. B.; DURAN, B. J.; SERVAIN, J. ; STUART . Mecanismos Atmosféricos Associados à Ocorrência de Precipitação Intensa sobre o Nordeste do Brasil durante Janeiro/2004. Revista Brasileira de Meteorologia, Cachoeira Paulista - SP, v. v.21, n. n. 1, p. 1-21, 2006.

ALVES, J.M., SOUZA, E.B., REPELLIE, C.A., FERREIRA, N.S. Um estudo da variabilidade pluviométrica no setor leste do nordeste brasileiro e a influência do fenômeno El Niño/Oscilação Sul.

Revista Brasileira de Meteorologia, vol. 12, n. 2, p. 25-39, 1997.

ALVES, J.M., TEIXEIRA, R.F.B., FERREIRA, A.G. Um Intenso Sistema Convectivo de Mesoescala no Setor Leste do Nordeste: O Caso de 20 a 21 de maio de 1999. Revista Brasileira de Meteorologia, vol. 16, n. 1, p. 19-31, 2001.

BASTOS, C. C.; FERREIRA, N. J. Análise climatológica da alta subtropical do Atlântico Sul. In: CONGRESSO BRASILEIRO 
DE METEOROLOGIA, 11, 2000, Rio de janeiro. Anais... 2000. p. 612-619. CD-ROM, Papel. (INPE-12473-PRE/7775). Disponível em: <http://urlib.net/sid.inpe.br/iris@1915/2005/03.15.19.20>. Acesso em: 31 jan. 2008.

BRITO, B. M.; LEVIT, V. ; FEDORAVA, N. ; SILVA, B. F. P. ; FIGUEIREDO E. L. ; CAVALCANTI, J. V. M. . Trovoada mais intensa nos últimos 10 anos em alagoas em fevereiro de 2008. Anais... In: XV CBMET Congresso Brasileiro de Meteorologia, São Paulo, 2008.

CALHEIROS, A. J. P.; MOLION, L. C. B.; VAZ, J. C. M.; TENÓRIO, R. S. Um evento de precipitação extrema sobre a costa leste do nordeste do Brasil. In: Congresso Brasileiro De Meteorologia, XIV - (CBMET), Florianópolis, SC. Proceedings... 2006. CDROM; Papel. (INPE-14543-PRE/9573). Disponível em: <http:// urlib.net/sid.inpe.br/mtc-m17@80/2006/12.26.11.56>.Acesso em: 1 fev. 2008.

CAMPOS, A. M. V.; FEDOROVA, N. Corrente de jato do nordeste brasileiro. In: XIV Congresso Brasileiro de Meteorlogia. Anais... 2006, Florianópolis.

CAVALCANTI, J. V. M. ; PONTES, B. F. ; BRITO, B. M. ; LEVIT, V. ; FEDORAVA, N. ; CRUZ, C. D. ; FIGUEIREDO E. L. . Verificação da previsão das precipitações intensas pelo modelo ETA de alta resolução no Estado de Alagoas. In: XV CBMET Congresso Brasileiro de Meteorologia. Anais... São Paulo, 2008.

COELhO-ZANOTTI, M. S. S. ; GAN, M. A. ; CONFORTE, J. C. . Estudo Da Variabilidade Da Posição E Da Nebulosidade Associada À ZCIT do Atlântico, Durante a Estação Chuvosa de 1998 e 1999 no Nordeste do Brasil. Revista Brasileira de Meteorologia, v. 19, p. 23-34, 2004.

COSTA, S. B. ; FEDOROVA, N. ; LEVIT, V. ; TEIXEIRA, E. R. . Precipitações extremamente intensas na perturbação ondulatória nos alísios em Alagoas nos dias 26 e 27 de junho de 2001. In: XIII Congresso Brasileiro de Meteorologia. Anais... 2004, Fortaleza.

COUTINHO, E. C., FISCH, G. Distúrbios Ondulatórios de Leste (Dols) na Região do Centro de Lançamento de Alcântara-MA. Revista Brasileira de Meteorologia, v.22, n.2, p. 193-203, 2007.

CRUZ, C. D. Determinação sinótica dos fatores que favorecem as influências frontais sobre o estado de alagoas. (MET-UFALMS-052) 138p. 2008. Dissertação (Mestrado em Meteorologia) - Universidade Federal de Alagoas, Maceió. 2008.

DOSWELL, C.A.; SCHAEFER, J.T. On the Relationship of Cirrus Clouds to the Jet Stream. Monthly Weather Review, v. 104, p. 105-106, 1976.

ESPINOZA, E. S. Distúrbios nos Ventos de Leste no Atlântico Tropical. 1996, 149p. Dissertação (Mestrado em Meteorologia) Instituto Nacional de Pesquisas Espaciais, São José dos Campos, 1996.

FEDOROVA, N., GEMIACKI, L., CARVALHO, L. C., LEVIT, V., RODRIGUES, L. R. L., COSTA, S. B. Frontal Zone on the North-East of Brazil. In: International Conference On Southern
Hemisphere Meteorology And Oceanography (Icshmo), 8., 2006. Foz do Iguaçu. Proceedings... São José dos Campos: INPE, 2006, p. 1765-1768. CD-ROM, 2006.

FEDOROVA, N., KRICHAK, S. O, LEVIT, V, CARVALHO, M. H., RODRIGUES, L. R. L. Verificação das trajetórias das parcelas de ar pelo modelo HYSPLIT no caso de CCM em Maceió-Alagoas. In: XIII Congresso Brasileiro de Meteorologia, Fortaleza. Anais... (CD-ROM), 2004.

FEDOROVA, N.; LEVIT, V.; FEDOROV, D. . Fog and Stratus Formation on the Coast of Brazil. Atmospheric Research, USA, v. 87, p. 268-278, 2008.

FERREIRA, N. S. Zona de Convergência Intertropical. Climanálise. In: Climanálise (Org). Boletim de Monitoramento e Análise Climática. Edição Especial de 10 anos. MCT/INPE. Cachoeira Paulista, SP. 1996. 235 p.

GAN, M. A.; KOUSKY, V. E. Vórtices ciclônicos da alta troposfera no Oceano Atlântico Sul. Revista Brasileira de Meteorologia, v. 1, p. 19-28, 1986.

GEMIACKI, L. Atuação de Sistemas Frontais na Estação Seca do Nordeste do Brasil. 121p. 2005. (MET-UFAL-MS-035). Dissertação (Mestrado em Meteorologia) - Universidade Federal de Alagoas, Maceió. 2005.

GOIS, G., SOUZA, J.L., SILVA, P.R.T., JÚNIOR, J.F.O. Caracterização da Desertificação no Estado de Alagoas Utilizando Variáveis Climáticas. Revista Brasileira de Meteorologia, v.20, n.3, p. 301-314, 2005.

GOMES, H. B. Estudo da Corrente de Jato próximo ao Estado de Alagoas.113p., 2003. (MET-UFAL-MS-019). Dissertação (Mestrado em Meteorologia) - Universidade Federal de Alagoas, Maceió. 2003.

HUBERT, L. F., KRUEGER, A. F. and WINSTON, J. S.: The double intertropical convergence zone - Fact or fiction? Journal of the Atmospheric Sciences, 26, 771-773, 1969.

INMET. Clima. Disponivel em: < http://www.inmet.gov.br/html/clima/ clima.html>. Acesso em 18 de outubro de 2008.

INMET. Manual de Observações Meteorológicas. 3.ed., Brasília: Ministério da Agricultura e do Abastecimento, p. 34/62-38/62, 1999.

KALNAY, E., K et al. The NCEP/NCAR 40-Year Reanalysis Project. Bulletin of the American Meteorological Society: 77, pp. $437-$ 472, 1996.

KOUSKY, V. E. Frontal Influences on Northeast Brazil. Monthly Weather Review, v. 107, n. 9, p. 1140-1153, set. 1979. KOUSKY, V. E., GAN, M. A. Upper Tropospheric Cyclonic Vortices in the Tropical South Atlantic. Tellus, v. 33, p. 538-551, Dez. 1981.

LEVIT, V., FEDOROVA, N., FERREIRA, G.C. Analise dos produtos do modelo ETA de alta resolução para o estado de Alagoas. Parte VII: Intensa trovoada em Maceió no dia 18 de janeiro de 2004. XIII Congresso Brasileiro de Meteorologia.Anais..., Fortaleza, CD, 2004.

MADDOX, R. A. Large-scale meteorological conditions associated with midlatitude, Mesoscale Convective Complexes. Monthly Weather Review, v. 111, p. 1475-1493, 1983. 
MADDOX, R. A. Mesoscale convective complexes. Bulletin American Meteorology Society. v. 61, p. 1374-1387. 1980.

MARQUES, J. Folha Online. Chuva já matou 104 pessoas este ano no Nordeste. Disponível em: $<$ http://www1.folha.uol.com.br/folha/ cotidiano/ult95u95887.shtml>. Acesso em 5 de fev. 2008.

MATTOS, A.; REIS, A. S. Influência da TSM sobre a ocorrência das chuvas no estado de Alagoas - Brasil. In: XIII Congresso Brasileiro De Meteorologia, 2004, Fortaleza, CE. Anais ..., 2004. v. CD. p. 1-10.

MISHRA, S. K.; RAO, V. B.; FRANCHITO, S. H. Genesis of NorthEast Brazil upper tropospheric cyclonic vortex: a primitive equation barotropic instability study. Journal of the Atmospheric Sciences, v. 64, p. 1379-1392, 2007.

MOLION, L.C.B.; BERNARDO, S.O. Uma revisão da dinâmica das chuvas no Nordeste Brasileiro. Revista Brasileira de Meteorologia, v.17, n.1, p. 1-10, 2002.

MOLION, L. C. B.; CALHEIROS, A. J. P. Eventos críticos no nordeste do Brasil: o evento de janeiro de 2004. In: XIII Congresso Brasileiro De Meteorologia, 2004, Fortaleza. Anais... Rio de Janeiro, RJ: SBMET, 2004.

MOLION, L. C. B.; FILHO, N. C.; SANTOS, T. V.; CAVALCANTI, A. S. As chuvas em janeiro de 2002 no estado de Alagoas: um evento secular. In: Congresso Brasileiro de Meteorologia, 2002, Foz Do Iguaçu. Anais..., 2002a.

MOLION, L. C. B.; SILVA, A. B. P. Extremos de precipitação sobre a costa leste do nordeste do Brasil: o evento de agosto de 2000. In: Congresso Brasileiro de Meteorologia, 2002, Foz Do Iguaçu. Anais..., 2002b.

PEZZI, L. P. ; ROSA, M. B. ; BATISTA, N. N. M. . A Corrente de Jato Subtropical na América do Sul. In: Climanálise. (Org.). Climanálise Especial - Edição Comemorativa de 10 Anos. 1 ed. Cachoeria Paulista - SP: CPTEC/INPE - ISSN 0103-0019, 1996.

PONTES DA SILVA, B. F.; FEDOROVA, N.; LEVIT, V.; BRITO, B. M.; SANTOS, A. G.; RAIMUNDO, C. C. Mecanismos associados às precipitações intensas observadas entre os dias 13 e 14 de janeiro de 2005 no sertão do estado de Alagoas. In: XV Congresso Brasileiro De Meteorologia, São Paulo, SP. Apresentação Oral, 2008a.

PONTES DA SILVA, B. F.; FEDOROVA, N.; LEVIT, V.; CAVALCANTI, J. V.; ROCHA, A. C. El Niño-Oscilação Sul e sua relação com as precipitações observadas no período chuvoso de Alagoas entre 2003 e 2006. In: XV Congresso Brasileiro De Meteorologia, São Paulo, SP. Poster, 2008b.

RAO, P.K., HOLMES, S.J, ANDERSON, R.K., WINSTON, J.S., LEHR, P.E., Weather Satellites: Systems, Data and Environmental Applications. Boston: American Meteorological Society, 503p., 1990.

RAO, V. B.; BONATTI, J. P. On the oringin of upper tropospheric cyclonic vórtices in the South Atlantic ocean and adjoining Brazil during the summer. Meteorology and Atmospheric physics, v. 37, p. 11-16, 1987.
REEDER, M. J., SMITH, R. K. Mesoscale Meteorology. In: Meteorology of the Southern Hemisphere. Boston: American Meteorological Society, v. 27, n. 49, p. 201-241, 1998.

RODRIGUES, L. R. L.; FEDOROVA, N. ; LEVIT, V. Trovoadas na costa leste do nordeste do Brasil associadas a interação entre ondas nos ventos de leste e VCAN. In: XIV Congresso Brasileiro de Meteorologia, 2006, Florianópolis. XIV Congresso Brasileiro de Meteorologia. Florianópolis : SBMET, 2006b. v. CD1.

SALVADOR. M. A. Anomalia de chuvas no mês de janeiro de 2002 em Alagoas. In: XIII Congresso Brasileiro de Meteorologia. 2004a. Fortaleza: CE. 2004. 1 CD-ROM.

SALVADOR. M. A. Chuvas extremas em alagoas durante janeiro de 2004. In: XIII Congresso Brasileiro de Meteorologia. 2004b. Fortaleza: CE. 2004. 1 CD-ROM.

SANTOS, E. V. Estudo qualitativo das previsões de tempo publicadas nos jornais Folha de São Paulo e Gazeta de Alagoas. 83p., 2008. Trabalho de Conclusão de Curso - Universidade Federal de Alagoas, Maceió. 2008.

SANTOS, F.A.S., AZEVEDO, P.V., SILVA, B.B. Previsão de Chuvas de Outono na Costa Este do Brasil. Revista Brasileira de Meteorologia, v.17, n.2, p. 195-205, 2002.

SILVA DIAS, M. A. F. Sistemas de mesoescala e previsão de tempo a curto prazo. Revista Brasileira de Meteorologia. v. 2. p. 133150. 1987.

SOUZA, I. F., COSTA, O. A. Atuação da frente fria no estado de Sergipe-outubro/1993. In: Congresso Brasileiro de Meteorologia, 8, Belo Horizonte, 1994. Anais..., v. 1, 149-151, 1994.

UFCG - UNIVERSIDADE FEDERAL DE CAMPINA GRANDE. Unidade Acadêmica de Ciências Atmosféricas. Clima. Dados Climatológicos do Estado de Alagoas. Disponível em: $<$ http:// www.dca.ufcg.edu.br/>. Acesso em: 1 de fev. de 2008.

UVO, C. R. B. e NOBRE, C. A. A Zona de Convergência Intertropical (ZCIT) e a precipitação no norte do Nordeste do Brasil. Parte I: A Posição da ZCIT no Atlântico Equatorial. Climanálise, v. 4, n. 07, p.34-40, 1989.

VALOVCIN, F.R. Infrared Measurements of Jet-Stream Cirrus. Journal of Applied Meteorology. v. 7, p. 817-826, 1968.

VAREJÃO-SILVA, M. A. Meteorologia e Climatologia Versão Digital 1. In:Perturbações Atmosféricas. Recife. 2005. p. 444-446.

VELASCO, I. e J. M. FRITSCH. Mesoscale Convective Complexes in the Americas. Journal of Geophysical Research, v. 92 (D8), XAVIER, T. M. B. S., XAVIER, A. F. S., SILVA DIAS, P. L., SILVA DIAS, M. A. F. A Zona de Convergência Intertropical - ZCIT e suas relações com a chuva no Ceará (1964-98). Revista Brasileira de Meteorologia, v. 15, n. 1, p. 27-43, 2000. 